\title{
Radial Slot Jet Impingement Flow and Heat Transfer on a Cylindrical Target
}

\author{
Neil Zuckerman* and Noam Lior* \\ University of Pennsylvania, Philadelphia, Pennsylvania 19104
}

\author{
DOI: $10.2514 / 1.20829$
}

\begin{abstract}
To better understand and facilitate design of an impinging jet device, the heat transfer on a cylindrical target exposed to radial impinging slot jets was investigated using numerical methods. Numerical models were created to test the performance of the shear stress transport, standard and realizable $k-\varepsilon, v^{2} f$, and Reynolds stress model turbulence models vs published test data. Based on the validation study, the $v^{2} f$ model was ultimately selected for further work. Models were then constructed to simulate a cylinder exposed to a radial array of slot jets. Parametric variations were conducted to produce information about the influence of jet speed, number of nozzles, and other independent design variables, upon heat transfer. The number of nozzles was varied from 2 to 8 , jet Reynolds number $R e$ from 5,000 to 80,000, and target diameter from 5 to 10 times the nozzle hydraulic diameter. The physics of the flows are discussed, finding, for example, that interaction of adjacent opposed wall jets caused a static pressure rise and resulted in flow separation on the surface of the cylindrical target. This separation and the fountain flow between the two wall jets greatly influenced the local heat transfer, causing a rise in Nusselt number $\mathrm{Nu}$ of an order of magnitude. The resulting average $N u$ values varied from 19 to 217 and were condensed into a correlation equation incorporating the ratio of nozzle width to target diameter, number of nozzles, Reynolds number, and Prandtl number.
\end{abstract}

\section{Nomenclature}

$A=$ target surface area, $\mathrm{m}^{2}$

$a_{n} \quad=$ correlation curve-fit parameter

$B \quad=$ slot jet nozzle width, $\mathrm{m}$

$c_{p} \quad=$ specific heat, $\mathrm{J} / \mathrm{kg} \cdot \mathrm{K}$

$D \quad=$ nozzle diameter, $\mathrm{m}$

$d \quad=$ target diameter, $\mathrm{m}$

$f \quad=v^{2} f$ relaxation function, $1 / \mathrm{s}$

$G \quad=$ jet mass flow per unit of target area, $\mathrm{kg} / \mathrm{s} \cdot \mathrm{m}^{2}$

$H \quad=$ nozzle-to-target spacing (nozzle height), $\mathrm{m}$

$h=$ convective heat transfer coefficient, $\mathrm{W} / \mathrm{m}^{2} \cdot \mathrm{K}$

$h_{\text {avg }}=$ area-averaged convective heat transfer coefficient, $\mathrm{W} / \mathrm{m}^{2} \cdot \mathrm{K}$

$k=$ turbulent kinetic energy, specific, $\mathrm{m}^{2} / \mathrm{s}^{2}$

$k_{c}=$ thermal conductivity, $\mathrm{W} / \mathrm{m} \cdot \mathrm{K}$

$L_{\text {nozzle }}=$ nozzle length, $\mathrm{m}$

$N u_{\text {avg }}=$ area-averaged Nusselt number

$N u_{0}=$ Nusselt number at stagnation point

$n=$ number of jets

$\operatorname{Pr} \quad=$ Prandtl number, fluid thermal diffusivity/fluid viscosity

$p \quad=$ fluid pressure, $\mathrm{Pa}$

$p_{s} \quad=$ static pressure, $\mathrm{Pa}$

$p_{t} \quad=$ total pressure, $\mathrm{Pa}$

$Q \quad=$ volumetric flow rate, for full target circumference, $\mathrm{m}^{3} / \mathrm{s}$

$q \quad=$ dynamic pressure $\left(0.5 \rho V^{2}\right), \mathrm{Pa}$

Re $\quad=$ Reynolds number, $U_{0} D / v$ for a jet

$r \quad=$ radial position, $\mathrm{m}$

$T \quad=$ temperature, $\mathrm{K}$

$T_{\text {jet }} \quad=$ jet temperature, exiting nozzle, $\mathrm{K}$

$T_{\text {wall }}=$ wall surface temperature, $\mathrm{K}$

$\mathrm{TR}=$ temperature ratio, $T_{\mathrm{wall}} / T_{\mathrm{jet}}$

Received 31 October 2005; revision received 17 January 2007; accepted for publication 11 February 2007. Copyright (C) 2007 by the American Institute of Aeronautics and Astronautics, Inc. All rights reserved. Copies of this paper may be made for personal or internal use, on condition that the copier pay the $\$ 10.00$ per-copy fee to the Copyright Clearance Center, Inc., 222 Rosewood Drive, Danvers, MA 01923; include the code 0887-8722/07 $\$ 10.00$ in correspondence with the CCC.

*Department of Mechanical Engineering and Applied Mathematics

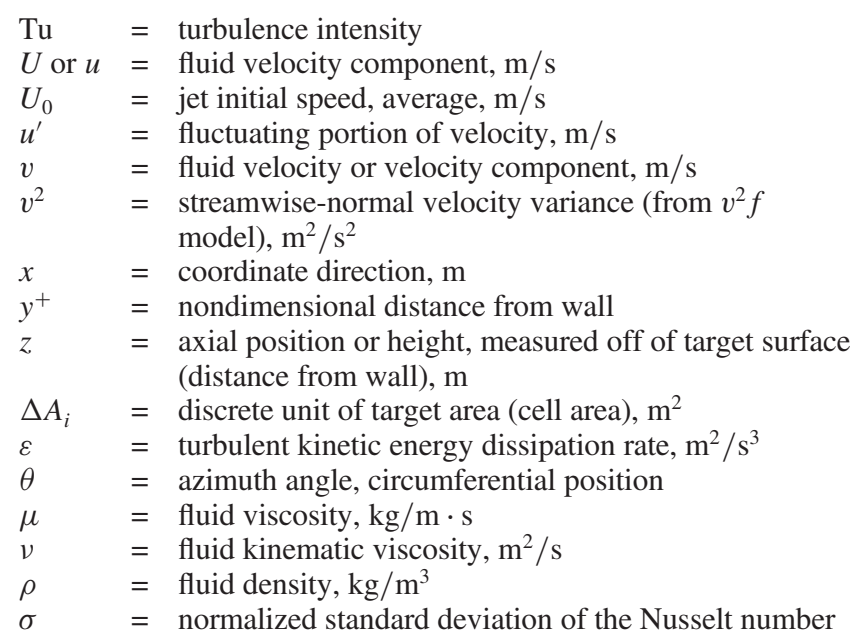

Subscripts

$\begin{array}{ll}\text { amb } & =\text { ambient } \\ \text { avg } & =\text { average (area-weighted) } \\ \min & =\text { minimum } \\ \max & =\text { maximum } \\ t & =\text { turbulent }\end{array}$

\section{Introduction}

$\mathbf{T}$ $\mathrm{HE}$ problem of heating or cooling a body with a curved surface using impinging jets is of interest in a variety of manufacturing processes and mechanical designs. Impinging jets are used for cooling and heating manufactured goods, temperature control of operating machinery, cooling of turbine blades and combustors, drying and defogging, and mass removal, including abrasion. Because of the thin boundary layer and the beneficial effect of turbulence, impinging jets may achieve desired heat transfer rates with a flow an order of magnitude lower than conventional parallelflow heat transfer designs. The physics and applications of these devices are detailed in many papers and a number of reviews [1-4].

The use of an array of narrow slot jets aligned with the axis of the cylinder, modeled in this paper, attains not only high heat transfer 
coefficients but also improved cooling uniformity. An application of interest (but only one of many) is the cooling of cylindrical targets such as shafts, end mills, drill bits, gears, and many other industrial products. The manufacturing process for the material includes a controlled quench to produce the desired grain size and phase composition, and consequently hardness. The quenching needs to be rapid and uniform, the first to attain the desired hardness, and the second to ensure uniform properties and minimal distortion during the process. For many reasons it is becoming increasingly desirable to use gases, instead of liquids, as quenchants [1]. Because gases offer lower cooling heat transfer coefficients than the more commonly used liquids, uniform jet impingement of the quenchant, with its high convective heat removal rates alongside with relatively low pumping energy penalty, is desirable.

Though slot jet impingement has been studied frequently, relatively little has been published about this configuration where the cylinder is cooled circumferentially. The most closely related material was found in Olsson et al. [5], which addressed single jets using high nozzle-to-cylinder diameter ratios (of order one) impinging on a cylinder placed against a wall, rather than the radial array examined herein.

The problem of simulating this device was approached in three steps. First, a literature search was conducted to understand the strengths and weaknesses of various numerical models applied to impinging jet problems (Zuckerman and Lior [6]). Next, a series of different turbulence models were used to examine their performance in simulating jet impingement cooling of a flat target under a round jet, a condition for which published test data were available. At the conclusion of this validation study, a model was selected by comparing the numerical results with published experimental results of velocity and heat transfer profiles. The study then proceeded by constructing numerical models of a cylindrical target under various radial slot jet configurations.

\section{Round Jet Impingement on Flat-Plate Model for Validation with Respect to Available Experimental Data}

\section{A. Validation Model Setup}

Because no complete experimental data were found for the case of slot jets impinging on a cylindrical target, the initial investigation and selection of numerical models was based on the models' ability to represent experimental data of a round jet impinging on a flat plate. This would provide a basis for numerical model selection and model validation.

The computational fluid dynamics (CFD) validation study began with an investigation of the steady Reynolds-averaged NavierStokes (RANS) models available in Fluent 6 [7]. The models were compared against the experimental data set of Baughn and Shimizu [8]. The particular data set selected was a case with $H / D=2$ and $R e=U D / v=23,750$. These experimental results feature a secondary peak in the heat transfer rate, known to be a difficult feature to predict numerically. The ability of a selected model to predict this feature supports its validity. In addition, some relevant experimental data for the same geometry were available from Baughn et al. [9] at $R e=23,300$. The data were provided in the form of local Nusselt number values at a sequence of radial positions on the target plate. Additional test data for this particular case were available in the form of wall-parallel velocity profiles at several radial positions [10].

The flat-plate models were constructed using structured quadrilateral grids. All cells used parallel boundaries meeting at $90 \mathrm{deg}$ (zero angular skew). The models used the 2-D axisymmetric solver [7]. The grid was constructed to include the full length of the supply pipe. The target plate and fluid domain were modeled out to a radius of nine jet diameters $(r=9 D)$ to match the full profile provided in the experimental data. The domain extended upwards to the height of the nozzle, as shown in Fig. 1, which also shows the various boundaries as well as the boundary type used at each surface.

The working fluid was taken to be air, and was assumed to be at a constant density $\rho$ and thermal conductivity $k_{c}$. Ambient pressure was set at $1 \mathrm{~atm}$ and fluid temperature was set at $300 \mathrm{~K}$. Because the

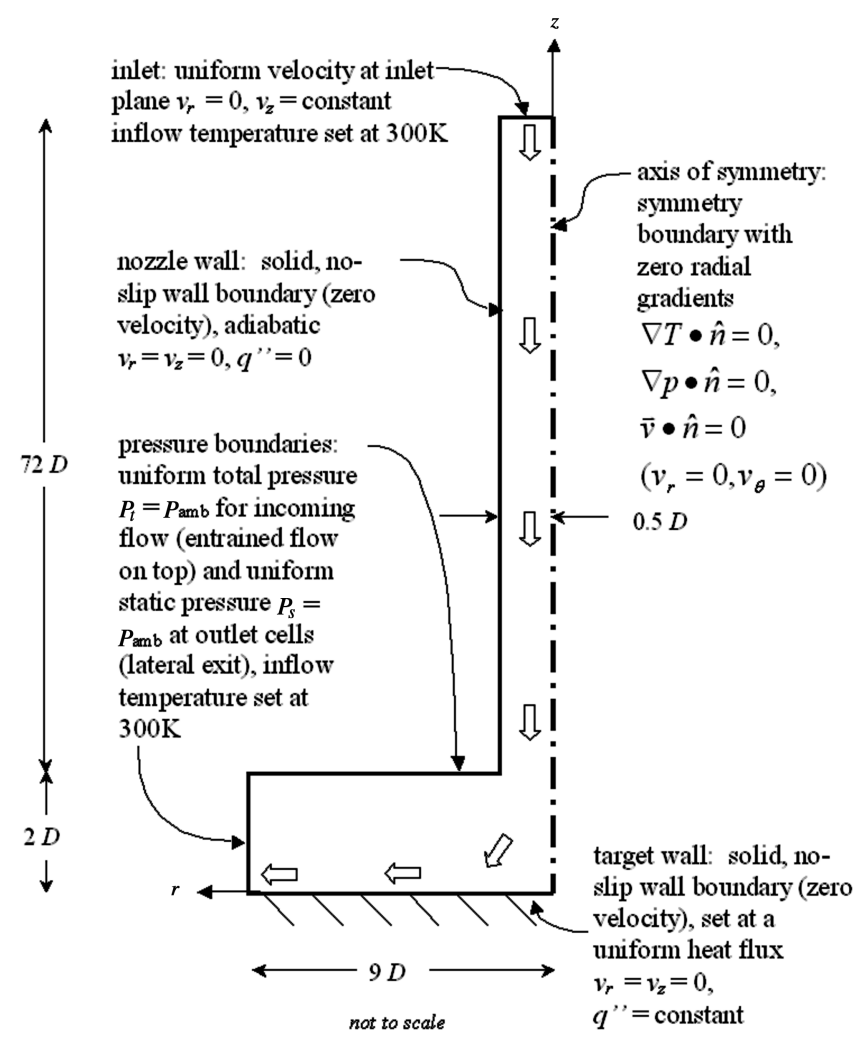

Fig. 1 Flow domain boundaries for the round impinging jet and flat target validation model.

results were correlated in a nondimensional form, the exact fluid properties were not critical to model validation. For a temperature difference of $10 \mathrm{~K}$, the change in Prandtl number is $0.2 \%$. As a extreme example, an increase in fluid temperature from $300 \mathrm{~K}$ to $1100 \mathrm{~K}$ would decrease the Prandtl number by $0.9 \%$. During the study these changes were found to be an order of magnitude smaller than the modeling error, as discussed in Sec. V.F.

The inflow at the start of the supply pipe (cylindrical nozzle) was set at a constant velocity and a temperature of $300 \mathrm{~K}$ and allowed to develop. Initial turbulence was set at $u^{\prime} / U=1 \%$ and was allowed to increase or decrease along the length of the pipe. With the very long supply nozzle $\left(L_{\text {nozzle }}=72 D\right)$, the solution was found to be insensitive to the nozzle inlet turbulence boundary condition.

The target wall and nozzle walls were modeled as nonslip surfaces. The surface of the target wall was set at a constant temperature, typically $15 \mathrm{~K}(\Delta T=15 \mathrm{~K})$ above the jet fluid temperature. Frictional (viscous) effects near the wall were modeled in different ways with the various models tested, as noted in Sec. II.B.

Steady solutions were performed using the segregated solver with implicit equations, standard pressure equations, the SIMPLE method for pressure-velocity coupling, and first-order-upwind differencing for the momentum, energy, and turbulent flow characteristics of each quadrilateral cell [7]. Underrelaxation was used for the pressure and momentum equations to provide stable convergence. Cell count was initially set at 44,000 cells, including boundary layer grids with a smallest cell length of $0.05 \mathrm{~mm}$. Further grid refinement was performed, as described in Sec. IV, to track the sensitivity of the results to grid density.

Using a $2.8 \mathrm{GHz}$ Pentium 4 microprocessor running Windows XP Professional with 2 GB of RAM, typical computation times were in the range of $1-5 \mathrm{~h}$. The CFD software used was Fluent release 6.1.22, Cortex version 3.5.6. Grid generation was conducted using GAMBIT 2.1.6.

\section{B. Selected Turbulence Models}

An earlier investigation of turbulence models by the authors [6] was used to select a modeling approach for the impinging jet 
problem. Steady RANS models were preferred based on computational effort required. Large eddy simulation (LES), direct numerical simulation (DNS), and other unsteady models were not used due to their very lengthy computation times. Based on the literature search, all of the following models were evaluated by running them and then comparing the results with the test data set:

1) Realizable $k-\varepsilon$ with standard wall functions ( $R k-\varepsilon$ equations from Shih et al. [11], wall functions based on Launder and Spalding [12], Jayatilleke [13]).

2) Realizable $k-\varepsilon$ with nonequilibrium wall functions (nonequilibrium wall functions from Kim and Choudhury [14]).

3) Realizable $k-\varepsilon$ with enhanced wall functions (enhanced wall functions based on White and Cristoph [15], Huang et al. [16]).

4) Reynolds stress model (RSM) with wall reflection effect and standard wall functions (from Launder et al. [17], plus equations for turbulent diffusivity and pressure strain, standard wall functions as listed for model 1. Pressure-strain and wall reflection models based on Gibson and Launder [18], Fu et al. [19], Launder [20,21]).

5) Reynolds stress model (RSM) with wall reflection effect and enhanced wall functions (enhanced wall functions as listed for model 3, pressure-strain and wall reflection models as listed for model 4).

6) Shear stress transport (SST) (based on $k-\varepsilon$ plus $k-\omega$ model of Wilcox [22]).

7) Standard $k-\varepsilon$ (based on Launder and Spalding [23], both standard wall functions and enhanced wall functions as noted for models 1 and 3).

8) $v^{2} f$ (by Durbin [24,25], Fluent add-on by Cascade Technologies).

The aforementioned references are those quoted as source material for the program code defining each model. The $v^{2} f$, examined further in the following sections, used the common eddy-viscosity model equations for mass conservation and momentum conservation, along with equations for turbulent kinetic energy, turbulence dissipation, streamwise-normal velocity variance $v^{2}$ and an elliptic relaxation function $f$, which modeled the effects of walls upon $v^{2}$. For brevity, the details are not listed in this paper. Further details, theory, and validation of this model are provided in Durbin [24,25]. The model constants were left at the program's default values of $C_{\mu}=0.22$, $C_{\varepsilon 1}=1.4, C_{\varepsilon 2}=1.9, C_{1}=1.4, C_{2}=0.3, C_{\eta}=70.0, C_{L}=0.23$, $\alpha=0.6, \sigma_{\kappa}=1.0, \sigma_{e}=0.85$, and $\sigma_{\varepsilon}=1.3$. Some of these model constants were slightly different than those published in other implementations [26]. Our implementation represented the latest published $v^{2} f$ model as written by its developers.

No radiation effects were incorporated into the models as the experimental data were already corrected for radiation effects. At the high Reynolds number involved, the Grashof number was two orders of magnitude smaller than the Reynolds number, giving $(\sqrt{G r} / R e) \ll 1$, so buoyancy effects were assumed to be negligible. In addition to the listed models, several other models were tested with unsatisfactory results.

\section{Results of the Simulation and its Validation for the Round Jet Impingement on a Flat Plate}

Figure 2 shows the profiles of Nusselt number vs radial position from the most successful models, and the test data, which we have previously shown [27]. Though no model produced a perfect result, some models produced visibly better results. The $v^{2} f$ model was the only model that produced the experimentally observed secondary peak in the Nusselt number profile.

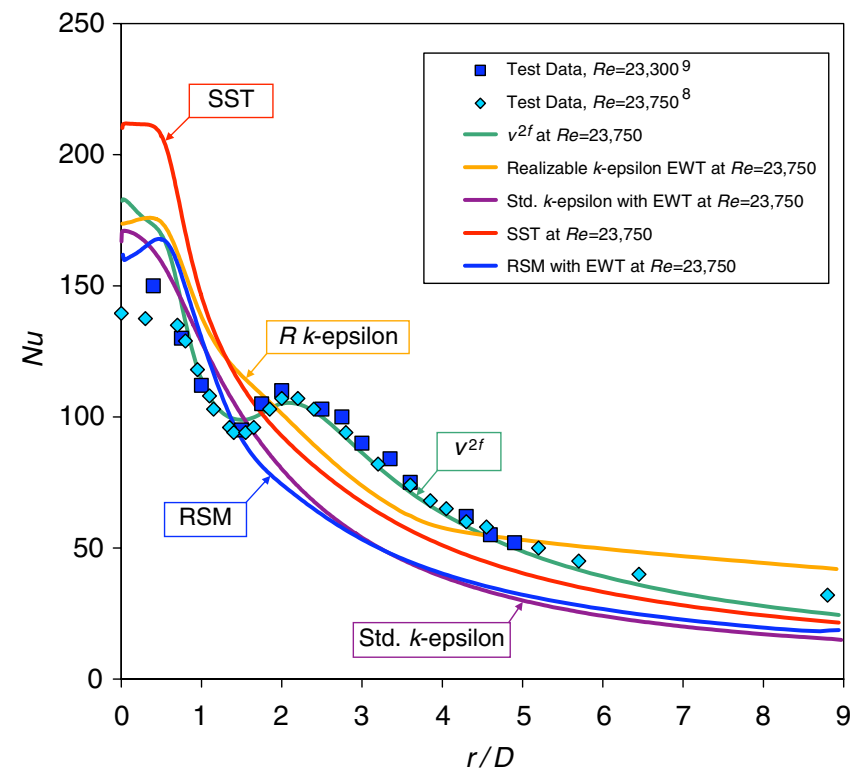

Fig. 2 Impinging jet Nusselt number profiles for the various turbulence models tested for the round jet impinging on a flat target, baseline firstorder models, $H / D=2$ [27].

All of the models overpredicted the Nusselt number in the stagnation region (at and around $N u_{0}$ ) from $r / D=0-1$. In the walljet region the models had greater variation in results, and for this test case the $v^{2} f$ model clearly surpassed the others. From $r / D=0.8$ and outwards to $r / D=6$, the $v^{2} f$ model tracked the experimental Nusselt number data within $10 \%$. In this region the $v^{2} f$ model fell within the expected error band of the experimental data and predicted a secondary peak in the right location with the right magnitude. In contrast, all of the other models tested predicted only a primary peak at $r / D=0$. Because of their inability to predict the secondary peak and their substantial underprediction in the wall-jet region, the RSM and standard $k-\varepsilon$ models were no longer considered for use. Table 1 summarizes the quantitative errors found with each model.

The wall-jet velocities were also compared against test data quoted in a similar study [10]. The velocities in the wall jets were compared vs test data at two different radial positions. At $r / D=1$, the $v^{2} f$ model provided the best prediction of velocity. At $r / D=2.5$ the SST and $v^{2} f$ models provided velocity profiles with similar levels of fidelity. Figures 3 and 4 show the profiles for the three favored models.

It was of interest to determine what physics of the $v^{2} f$ model allowed it to predict the secondary peak in the Nusselt number. Figure 5 shows a velocity field contour map for the $v^{2} f$ model. After the flow passed over the stagnation region, the favorable pressure gradient caused it to accelerate again, with the highest speed at $r=1.5$. After this region the flow was no longer influenced by the high static pressure of the stagnation region, and its progress was then influenced by inertia, by viscous effects in the upper and lower shear layers of the wall jet, and by the natural deceleration of any outwardaligned axisymmetric radial wall jet (due to mass conservation, an effect independent of viscosity). We can see that, as expected, the accelerating wall jet had progressively higher levels of turbulence from $r / D=0.5$ to $r / D=2$. The region of highest $k$ immediately adjacent to the wall corresponded to the region of the secondary peak

Table 1 Total CFD model error for the round jet impinging on a flat-plate problem [27]

\begin{tabular}{lccc}
\hline \hline Model & $\begin{array}{c}\text { \% error in } N u \text { in } \\
\text { stagnation region }\end{array}$ & $\begin{array}{c}\text { Max. \% error in } N u \text { in } \\
\text { wall jet, } 2<r / D<5\end{array}$ & $\begin{array}{c}\text { Max. \% error in } N u \text { in } \\
\text { wall jet, } r / D \geq 5\end{array}$ \\
\hline SST & +50 & -25 & -31 \\
$v^{2} f$ & +30 & -5 to +5 & -22 \\
Realizable $k-\varepsilon$ & +22 & -19 to +6 & +30 \\
Standard $k-\varepsilon$ & +22 & -40 & -53 \\
RSM & +16 & -40 & -40 \\
\hline \hline
\end{tabular}




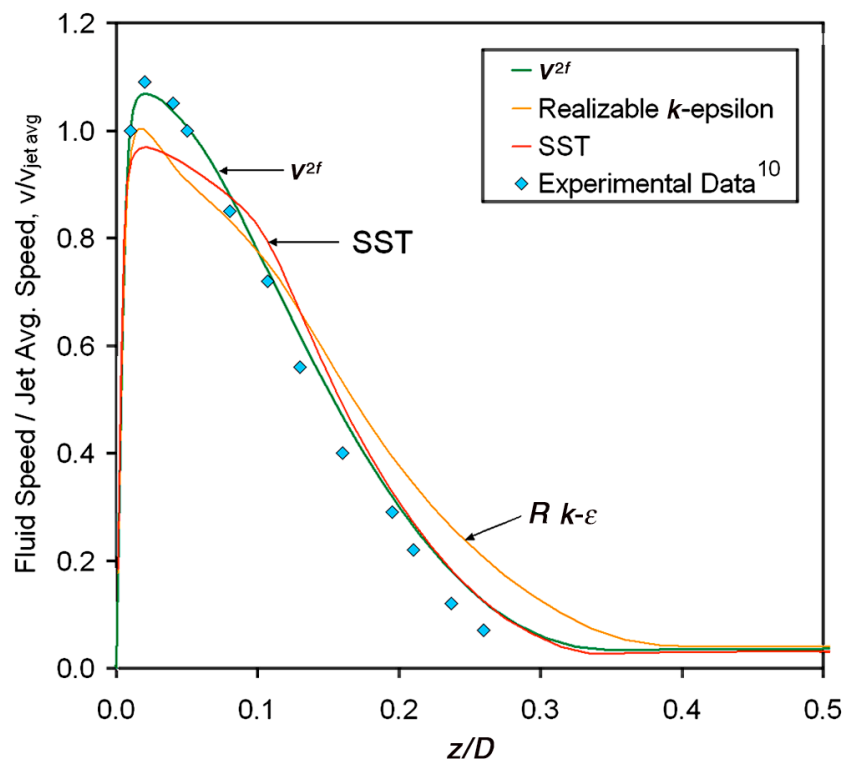

Fig. 3 Comparison of the fluid velocity axial distribution at $r / D=1$ of the three preferred models with experimental results, for the round jet impinging on a flat target; $R e=23,750, H / D=2$, nozzle at $z / D=2$ [27].

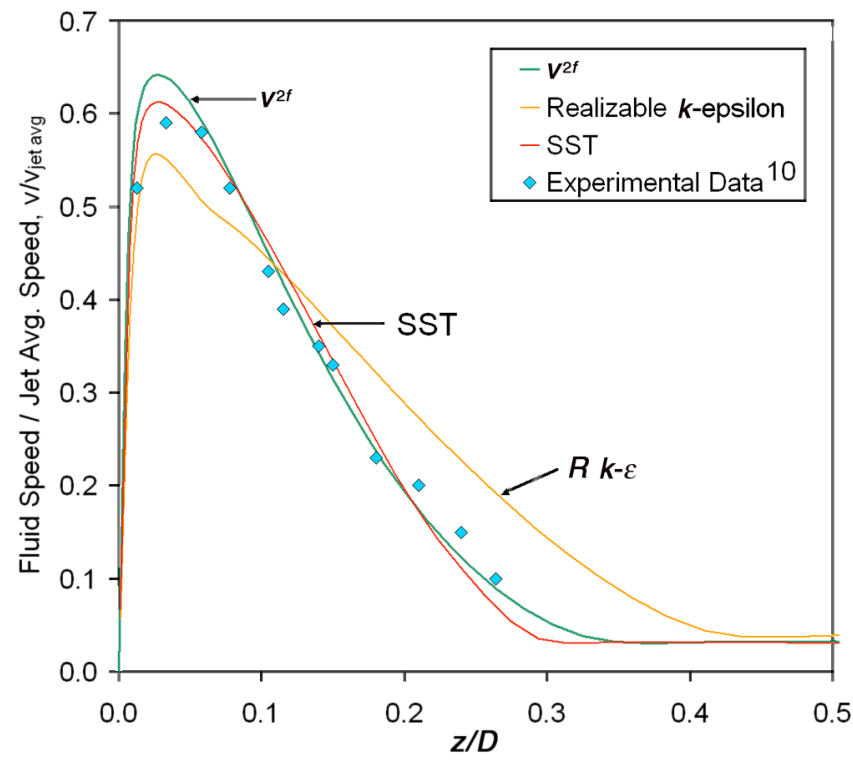

Fig. 4 Fluid velocity magnitude profile at $r / D=2.5$ for the three preferred models, tested for the round jet impinging on a flat target; $\operatorname{Re}=23,750, H / D=2$, nozzle at $z / D=2[27]$.
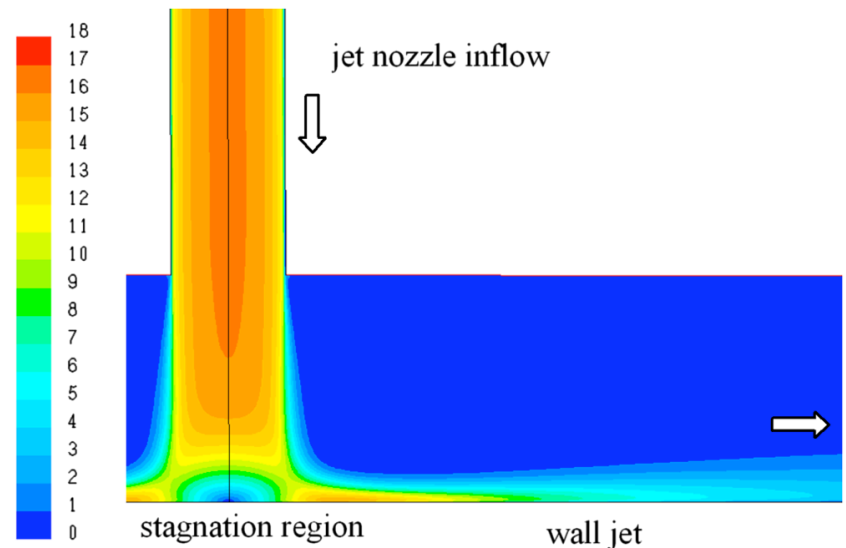

stagnation region

wall jet

Fig. 5 Velocity field contours (in $\mathrm{m} / \mathrm{s}$ ) for the $v^{2} f$ model; $R e=23,750$, $H / D=2$ [27].

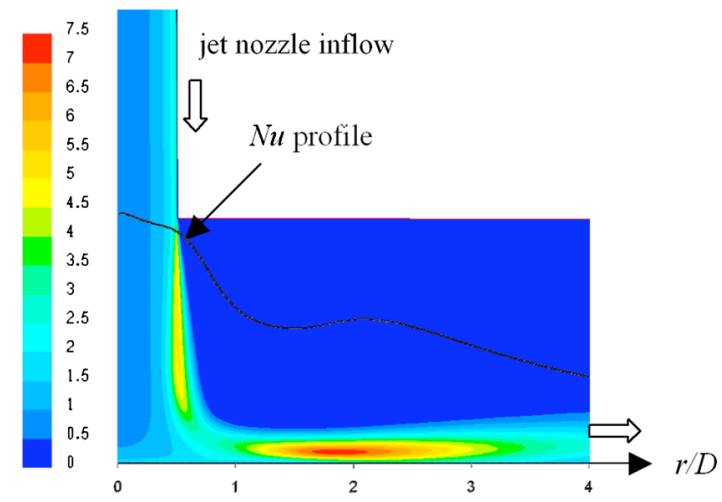

Fig. 6 Turbulent kinetic energy contours for $v^{2} f$ model in $\mathrm{m}^{2} / \mathrm{s}^{2}$, shown with the radial distribution of Nusselt number; $R e=23,750$, $H / D=2$ [27].

in Nusselt number, and so this peak can be attributed to development of turbulent flow in the wall jet. This is illustrated in Fig. 6. Beyond this region the deceleration of the flow and decay of the wall-jet boundary layer caused a net reduction in turbulence and a decrease in Nusselt number. The other models were unable to predict the secondary peak because they produced different and likely incorrect velocity and turbulent kinetic energy fields, which directly influenced the thermal energy transfer calculations. The fourequation $v^{2} f$ model resolved the complete boundary layer and included the variable $f$, which tracked the damping effects of walls on $v^{2}$, the wall-normal (streamwise-normal) component of turbulent velocity fluctuation [24,25]. This feature was unique to the $v^{2} f$ model and enabled it to more closely model the effects of the wall on the turbulent wall jet.

\section{Examination of Grid and Discretization Order Dependence}

As shown, the selection of a baseline model with a 44,000-cell grid and first-order discretization scheme with the $v^{2} f$ model produced results that are validated to a satisfactory degree by the available experimental results. It was, however, of interest to further examine grid and disctretization order dependence, and additional computations were made: 1) at a four-fold higher cell count and then 2) with the original grid resolution using second-order shape functions (permitting quadratic variation of calculated variables between cell edges). Figure 7 presents a comparison of the radial distributions of the Nusselt number for these different settings. Figures 8 and 9 show the effects of the same three variations of grid/shape function on the

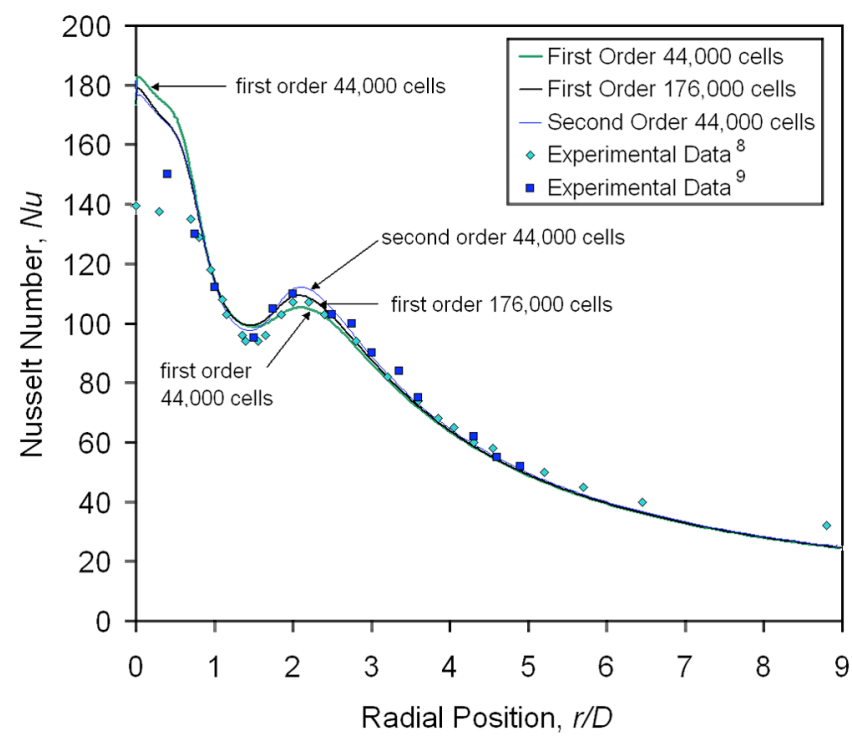

Fig. 7 Comparison of the computed radial distributions of Nusselt number for the three $v^{2} f$ model grid densities and the two discretization method orders, with experimental results, for the round jet impinging on a flat target; $R e=23,750, H / D=2$, nozzle at $z / D=2$. 


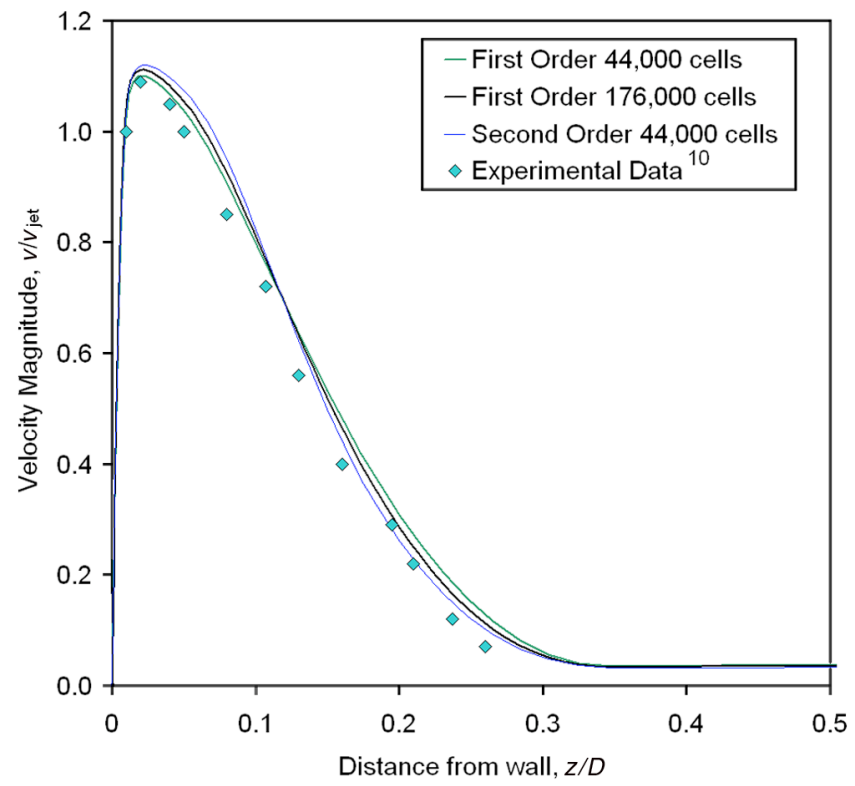

Fig. 8 Comparison of the computed fluid velocity at $r / D=1$ for the three $v^{2} f$ model grid densities and the two discretization method orders, with experimental results, for the round jet impinging on a flat target; $R e=23,750, H / D=2$, nozzle at $z / D=2$.

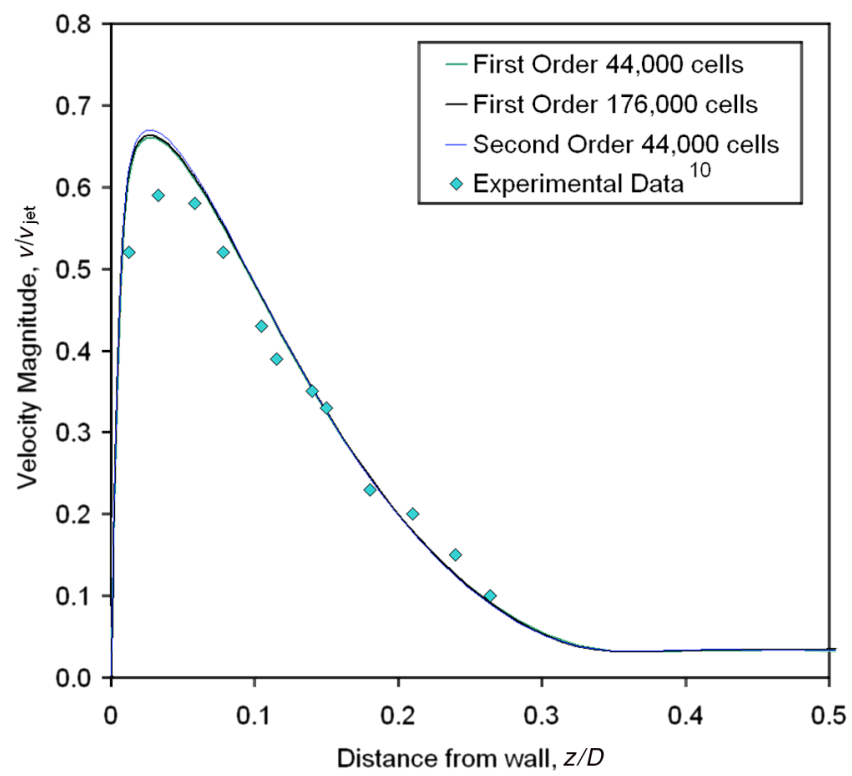

Fig. 9 Comparison of the computed fluid velocity at $r / D=2.5$ for the three $v^{2} f$ model grid densities and the two discretization method orders, with experimental results, for the round jet impinging on a flat target; $R e=23,750, H / D=2$.

axial velocity distributions. The profiles resulting from these variations were found to be very close together, with insignificant differences. It was concluded that the great majority of the difference between the experimental data and the computed results was the outcome of differences between the computational model physics and the experimental reality (i.e., modeling error) rather than the result of grid coarseness or discretization model order. This modeling error varied with target location, ranging from $2 \%$ in parts of the wall jet to a maximum of $26 \%$ in the stagnation region.

Based on the results of this modeling study, the $v^{2} f$ model was selected for further use. For the model used, the predicted value of the area-weighted Nusselt number $\left(N u_{\text {avg }}\right)$ over $0<r / D<9$ was $N u_{\text {avg }}=47$, compared to the experimental result of $N u_{\text {avg }}=51$. This overall error of $8 \%$ came primarily from the two regions where $r / D<0.8$ and $r / D>5$.

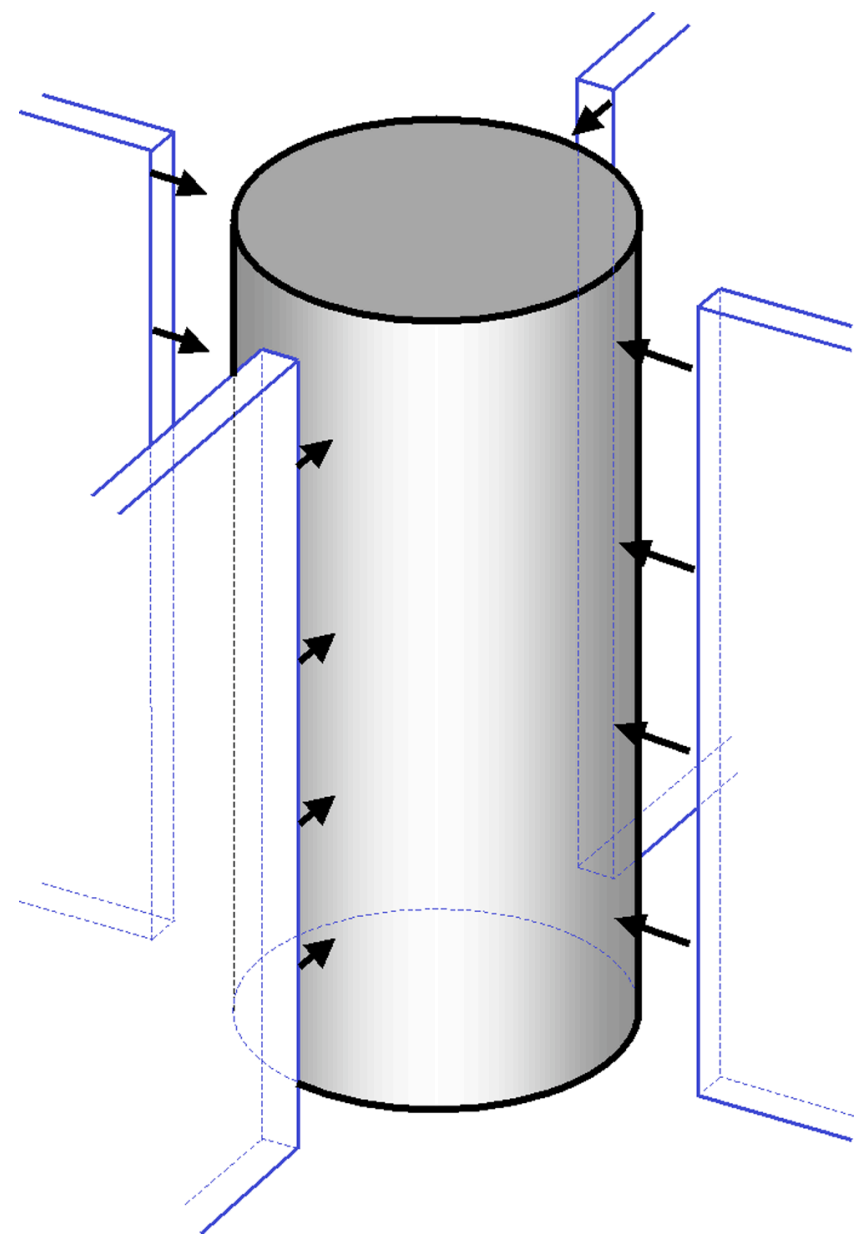

Fig. 10 Isometric view of the target and the slot jet nozzles.

\section{Modeling of a Cylinder Under Radially Impinging Slot Jets}

Following the validation work, the $v^{2} f$ model with first-order discretization was selected for use in the following parametric study of jet impingement heat transfer on a solid cylindrical target. As discussed in Sec. IV, model parameters such as $y^{+}$were selected to match or exceed the resolution used in the validation study, and the thinnest region of the wall-jet velocity boundary layer was covered by at least $50-60$ cells and the stagnation region thermal boundary layer was covered by 7-25 cells for the various cases studied, with typical thermal boundary layer thicknesses in the range of 15 cells. The impinging jet arrangement used a uniformly spaced set of slot jets pointed radially inward at a circular cylinder, with the long dimension of the jet nozzle parallel to the cylinder axis, as shown (for four jets) in Fig. 10. The purpose of the computations was to calculate the magnitude and variation of the heat transfer coefficient (expressed as the Nusselt number) on the surface of the cylindrical target as a function of the major physical parameters including $R e, n$, $d / D, H /(2 B)$, and $P r$.

\section{CFD Model Setup}

The section of the cylinder under investigation was modeled in two dimensions, and represented a central section of a cylindrical target in an enclosure with end walls (Fig. 11). For a case with a long cylinder (axial length $>10 \mathrm{D}$ and axial length $>10 H$ ), the effects of the end walls would be small, and the steady component(s) of the velocity field at the central axial plane would be in plane (i.e., all in the radial and azimuthal directions). The mean flow velocities in the model were thus constrained to a plane perpendicular to the axis of the cylinder, and the mean velocity component in the axial direction was set to zero.

The selection of the radial jets distributed uniformly around the cylinder circumference created an arrangement where the flowfield 


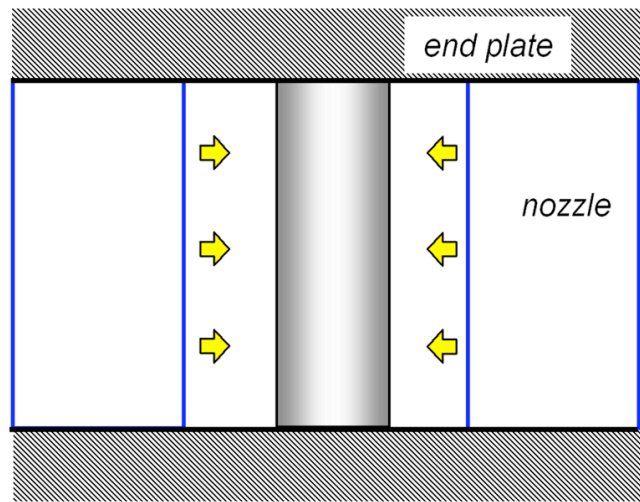

Fig. 11 Side view of a cylindrical target showing end plates; arrows indicate freejet direction.

and heat transfer would vary in the space between the jet positions, but the pattern would repeat around the circumference of the cylinder as all jet nozzles supplied the same flow. The time-averaged turbulence model selected for the problem would not resolve the instantaneous (and perhaps asymmetrical) motion of eddies in the air. Enlarging the solution domain would instead degrade the rate of model convergence, but upon proper convergence would produce a symmetrical solution. The geometric symmetry was used to reduce the computational domain of the problem. For example, in a case with four slot jet nozzles evenly spaced at 90 deg of circumference $(n=4)$, it was assumed that all four flow regions had the same characteristics, and thus only one region was modeled. The symmetry of the nozzle about its own center allowed further reduction of the domain, so that for the case with four nozzles, only $45 \mathrm{deg}$ of circumference was included in the computational domain. Schematics of the geometry are shown in Figs. 10-12 for a sample case with $n=4$, and the corresponding 45 deg computational volume is shown in Fig. 13. Figure 14 shows a coarse-resolution schematic of the quadrilateral-cell grid alignment within the domain, which followed the contours of an "O" grid. Cell density was varied to provide high resolution with maximum $y^{+}$in the wall region ranging between 0.3 and 2.0. Total cell count for the models ranged from 30,000 to 120,000 , with the higher values more common.

The jet target was modeled as a solid wall of constant temperature. The flow at the nozzle inlet was set at an ambient temperature and had a radially uniform initial velocity with $1 \%$ turbulence intensity. This fluid flowed through the nozzle, with the no-slip condition at the nozzle walls, until reaching the nozzle exit. The outflow region was modeled as a constant-static-pressure boundary, allowing backflow at a total pressure equal to the ambient static pressure (due to possible entrainment).

A sample case was selected with $n=4$ and $R e=20,000$ to study the effects of changes in the grid density and shape function. The

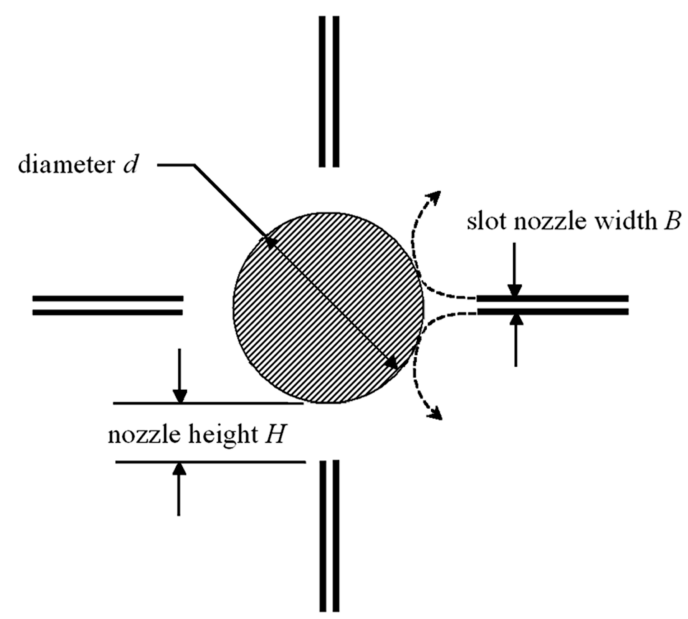

Fig. 12 Top view of sample model geometry for the cylindrical target under radial slot jets, $n=4$ case.

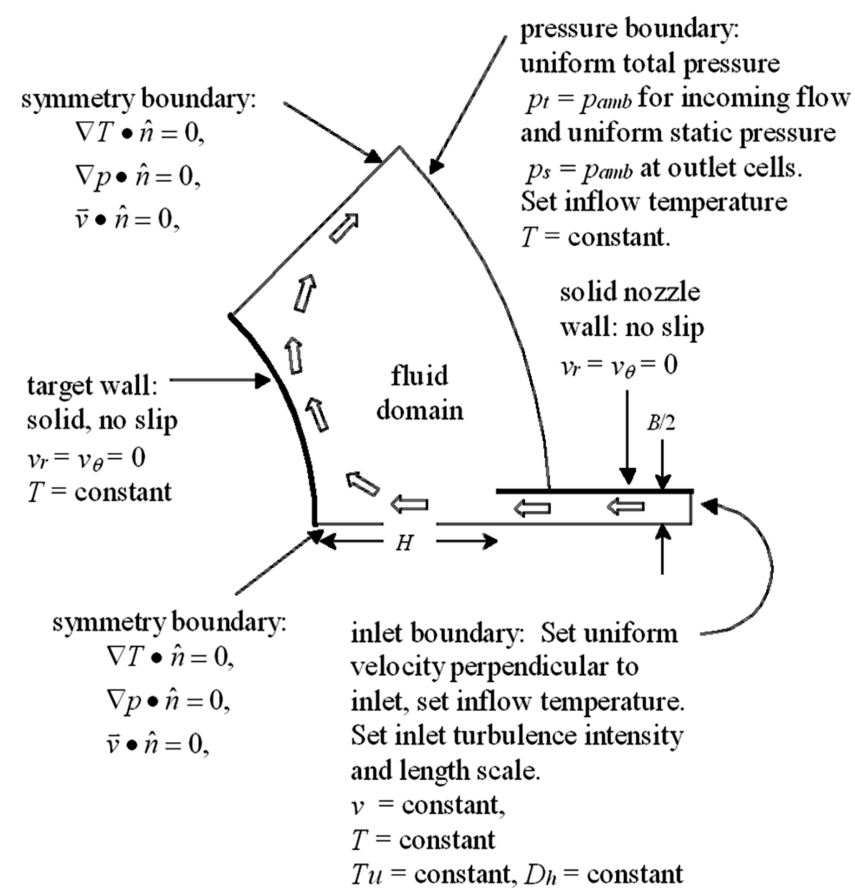

Fig. 13 Computational volume for the cylindrical target under radial slot jets, $n=4$ case.

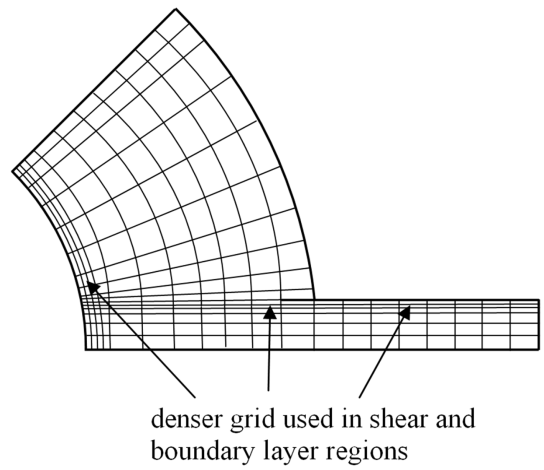

Fig. 14 A rough schematic of the computational grid for $n=4$.

calculations for this case were performed for three different grid densities and two choices of shape function. Figure 15 shows the resulting Nusselt numbers. The 81,700 cell, first-order case had a grid density and shape function corresponding to those used in our models of jet impingement on cylindrical targets.

With variations in cell count and model complexity, the required computation time varied from 1 to $30 \mathrm{~h}$, using a $2 \mathrm{GHz}$ Athlon 64 $3200+$ microprocessor running Windows XP Professional 2002 with $1 \mathrm{~GB}$ of RAM. The CFD software used was Fluent release 6.1.22, Cortex version 3.5.6. Grid generation was conducted using GAMBIT 2.1.6.

\section{Parametric Variation}

\section{A. Range of Parameters}

The parametric variations used in the study focused on the influences of geometric variables and of fluid properties. The majority of the models used air as the fluid. The study also included models with a cylinder submerged in water (liquid) and also using pure steam, to calculate the effect of changing the Prandtl number. The primary independent variables included the ratio of cylinder diameter to jet nozzle diameter $(d / D)$, nozzle hydraulic diameter $(D$ or $H / 2 B)$, number of equally spaced radial nozzles $(n)$, and flow Reynolds number $(R e=U D / v)$. The jet impingement device was modeled with values of $d / D$ equal to $5,7.5$, and 10 . The number of 


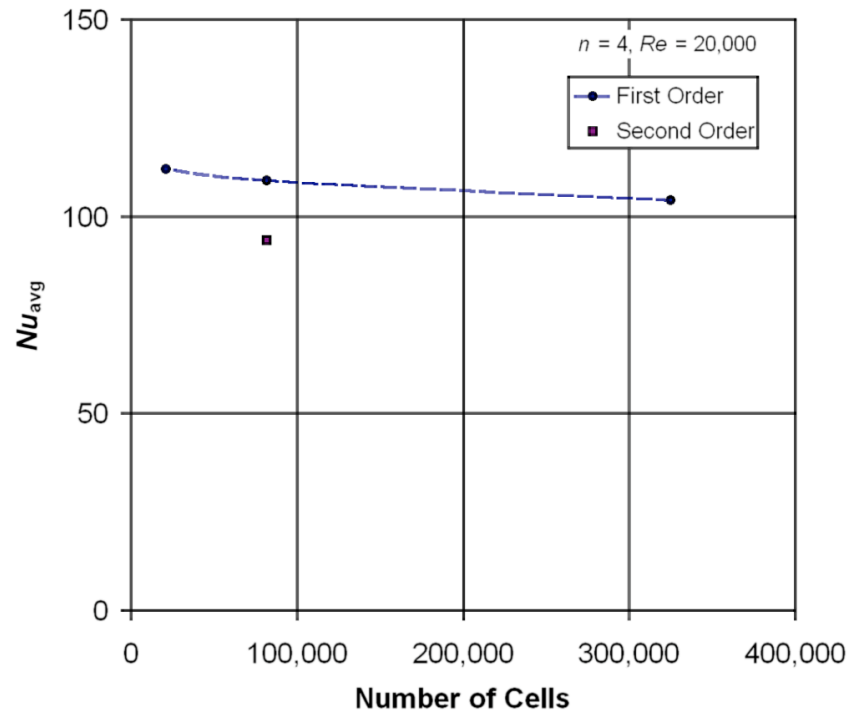

Fig. 15 Average Nusselt number for various grid densities and shape functions, for the jet impinging on a circular cylinder; $n=4$, $R e=20,000, H / 2 B=3$.

jet nozzles $n$ was 2, 4, 6, and 8. Jet height $H / 2 B$ was set at 1,3 , and 5 . For each combination of these parameters, the nozzle entry speed was varied to model four to six different cases with Reynolds numbers in the range of 5,000 to 90,000 .

\section{B. Nature of the Flow}

Figure 16 shows, for the case of four jets $(n=4)$, a view of velocity magnitude contours in half of the flow domain, combined with a polar plot of the Nusselt number. This pattern is generally similar for all computed cases. The corresponding nondimensional parameters are $R e=20,000, d / D=10, H / 2 B=3, n=4$. Though a wide variety of $R e, d / D, H / 2 B$, and $n$ were used in the models, this particular case is used here as an example to illustrate the flowfield properties. The velocity field shows distinct freejet, stagnation, walljet, and fountain regions. A separation point on the wall is also clearly visible. Noteworthy is the existence of relatively very high Nusselt

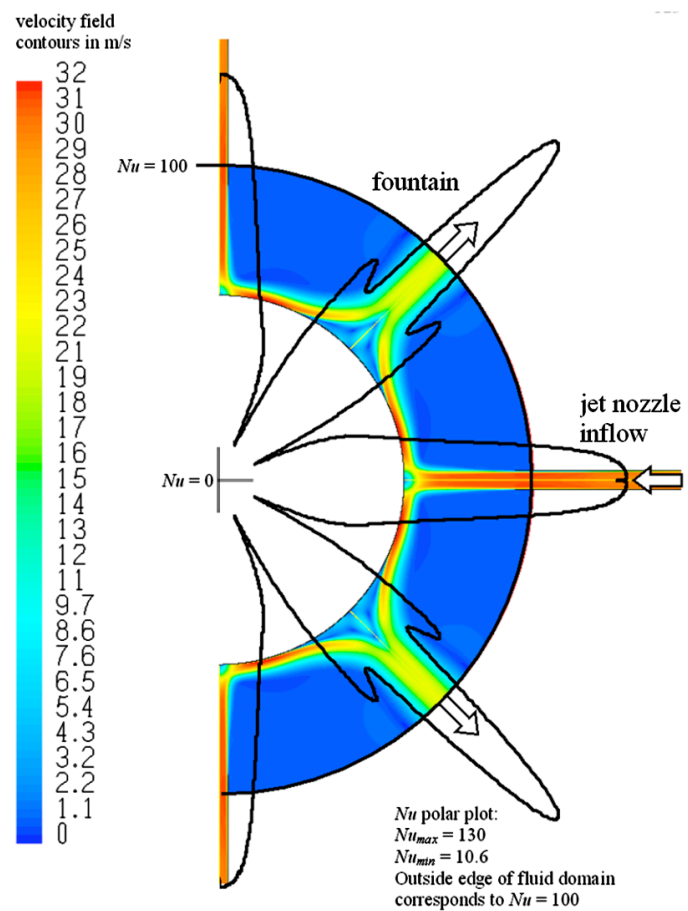

Fig. 16 Velocity field in $\mathrm{m} / \mathrm{s}$ with Nusselt number polar plot, for the $R e=20,000, d / D=10, H / 2 B=3, n=4$ case number peaks at the stagnation and fountain regions. To better understand the flow and Nusselt number fields, further details ( $k$ and $\varepsilon)$ of the computed flow are shown and discussed next.

Figure 17 shows contours of turbulence kinetic energy $k$ in the flowfield. We can identify three regions of high turbulence: in the shear layer at the edge of the freejet region, in the middle of the walljet running parallel to the wall, and in the fountain region under the separated jet. For this problem all three regions had peak turbulent kinetic energy of the same order of magnitude. One clear feature of this $v^{2} f$ simulation, which agreed well with available experimental measurements, was that the stagnation region turbulent kinetic energy was lower than that of the shear layer. In contrast, other numerical models such as the $k-\varepsilon$ model are known to grossly overpredict the turbulence in the center of the jet. As expected, the level of $v^{2}$ increased and decreased along with the level of $k$.

The levels of the turbulent kinetic energy dissipation rate $\varepsilon$ are presented in Fig. 18. We see that for this problem the regions of highest dissipation were the same as the regions of highest energy.

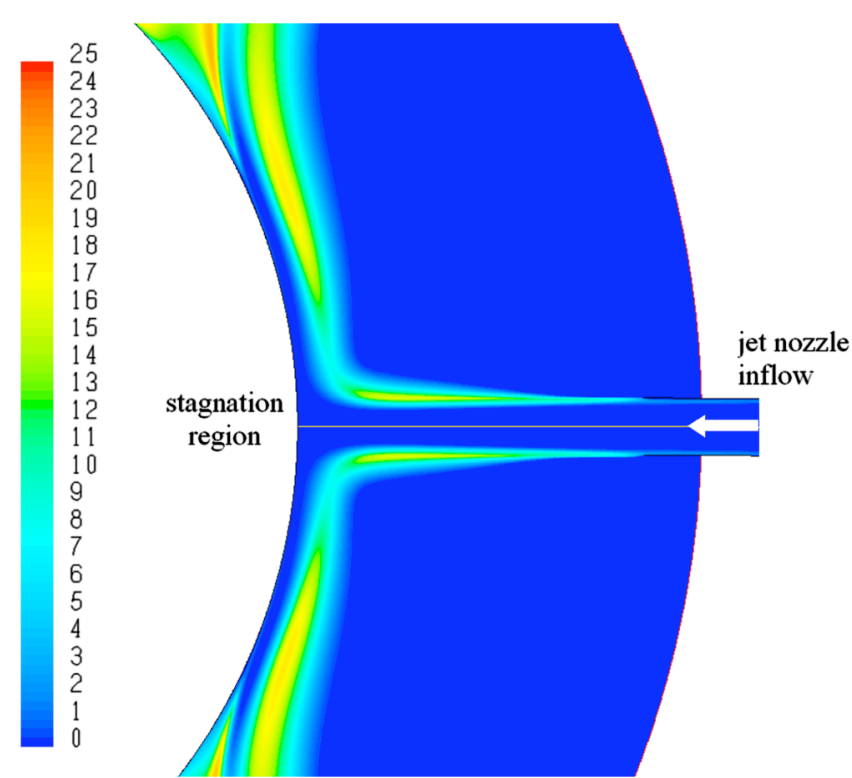

Fig. 17 Specific turbulent kinetic energy $k$ in the freejet and wall jet, in $\mathrm{m}^{2} / \mathrm{s}^{2}$, for the $R e=20,000, d / D=10, H / 2 B=3, n=4$ case.

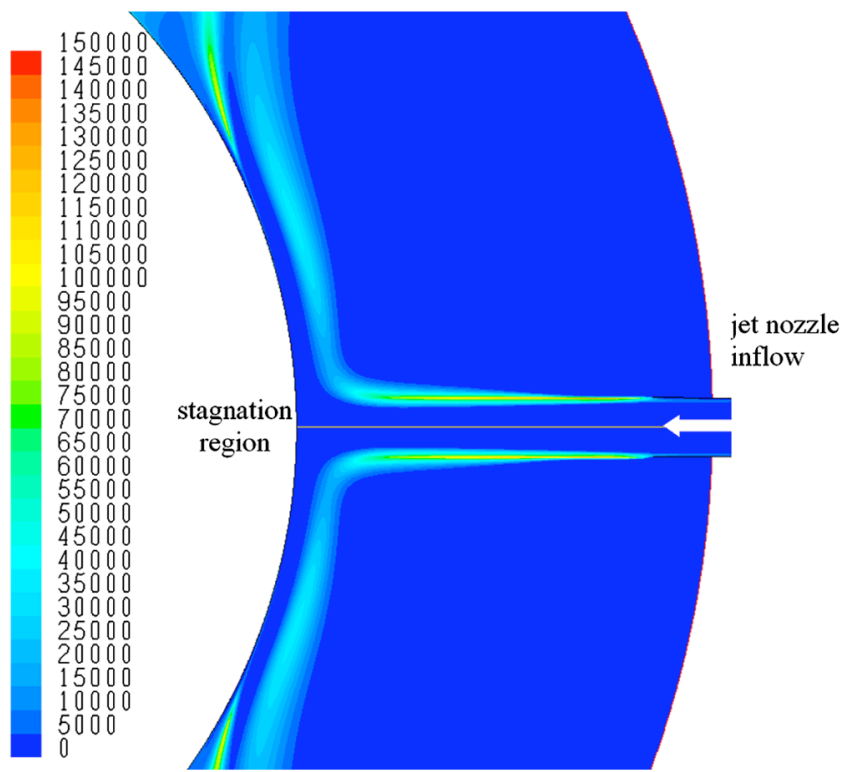

Fig. 18 Turbulent kinetic energy dissipation rate $\varepsilon$ in $\mathrm{m}^{2} / \mathrm{s}^{3}$, for the $R e=20,000, d / D=10, H / 2 B=3, n=4$ case. 
This may be inferred in advance by noting the presence of the same production term in both the $k$ and $\varepsilon$ equations [7]. One can also see that the highest levels of $\varepsilon$ occurred in the shear layer and that these levels were greater than those seen in the wall jet.

\section{Circumferential Distribution of the Nusselt Number}

The dependent variable of greatest practical interest was the Nusselt number. Figure 19 shows the Nusselt number distribution along the cylinder surface circumference for the same data set presented earlier, as well as that for higher values of $n$. This plot includes each of 550 wall cell values, reflected about the jet center plane to include individual data points from 1100 finite cells.

The Nusselt number distribution for the cylinder was significantly different than that seen in the case of the flat wall (shown in Figs. 6 and 7). As seen in the single jet on a flat target, the Nusselt number decreased in the wall jet moving outward from the stagnation point. However, examination of the velocity field for the jet on the cylindrical target showed detachment of the jet around 23 deg of azimuth, one-quarter of the way between neighboring jet nozzles and halfway between the stagnation point and the fountain. The transfer properties downstream of the separation point were governed by the transport under a strong recirculating fountain. The minima of the Nusselt number occurred at and just downstream of the separation point. The pattern of a large peak in Nusselt number under the fountain was common to all of the selected values of $n$, as shown in Fig. 19. Increases in $n$ did not affect the local Nusselt number in the stagnation region, but resulted in a more confined flow and shorter wall jet.

The flow and the Nusselt number profiles at different values of the Reynolds number were similar to the sample case shown here, but had different magnitudes. Figure 20 shows the velocity field for a case with $R e=80,000, d / D=10, H / 2 B=3$, and $n=8$. The increase in both Reynolds number and $n$ produced a very high $N u_{\text {avg }}$; here $N u_{\text {avg }}=202$ vs 63 for the $R e=20,000, n=4$ case shown previously. Visually apparent differences between this highReynolds number eight-jet geometry and the four-jet geometry were the higher ratio of fountain core velocity and nozzle exit velocity (now up to 0.8), and the much shorter wall jet. The wall-jet region extended for about one nozzle width $(1 B)$ beyond the stagnation region before it detached, compared to a wall-jet length of $4 B$ for the $n=4$ case. The various cases modeled showed the relative magnitude of fountain velocity magnitude vs nozzle exit velocity magnitude depended primarily on the Reynolds number, and the circumferential span of the wall jet depended primarily on $n$.

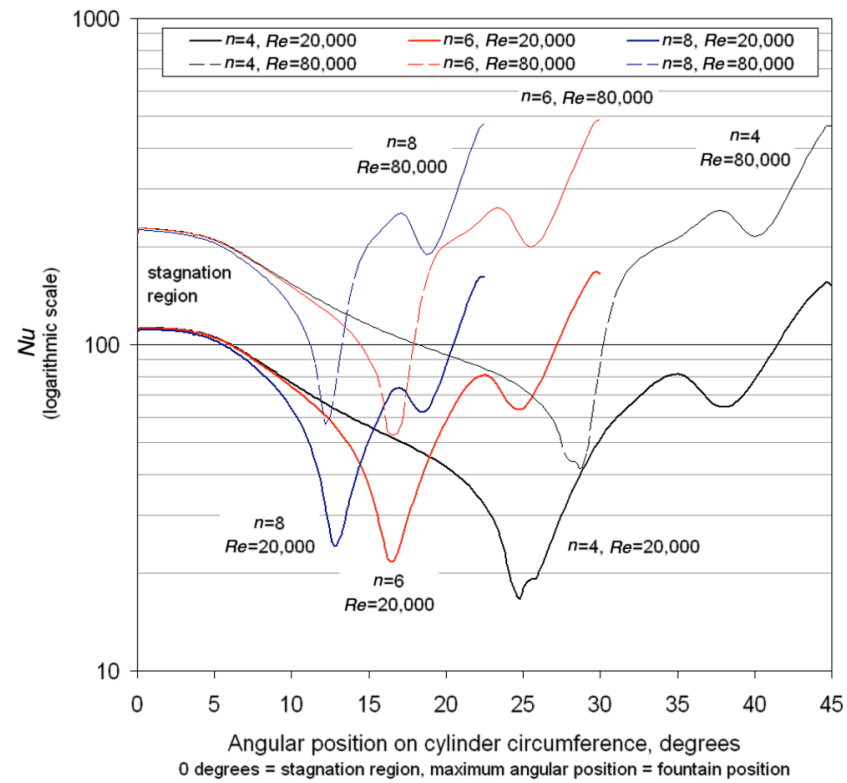

Fig. 19 Distributions of Nusselt number with circumferential position for various values of $n$, for $R e=20,000$ and $80,000, d / D=7.5$, $H / 2 B=3$.

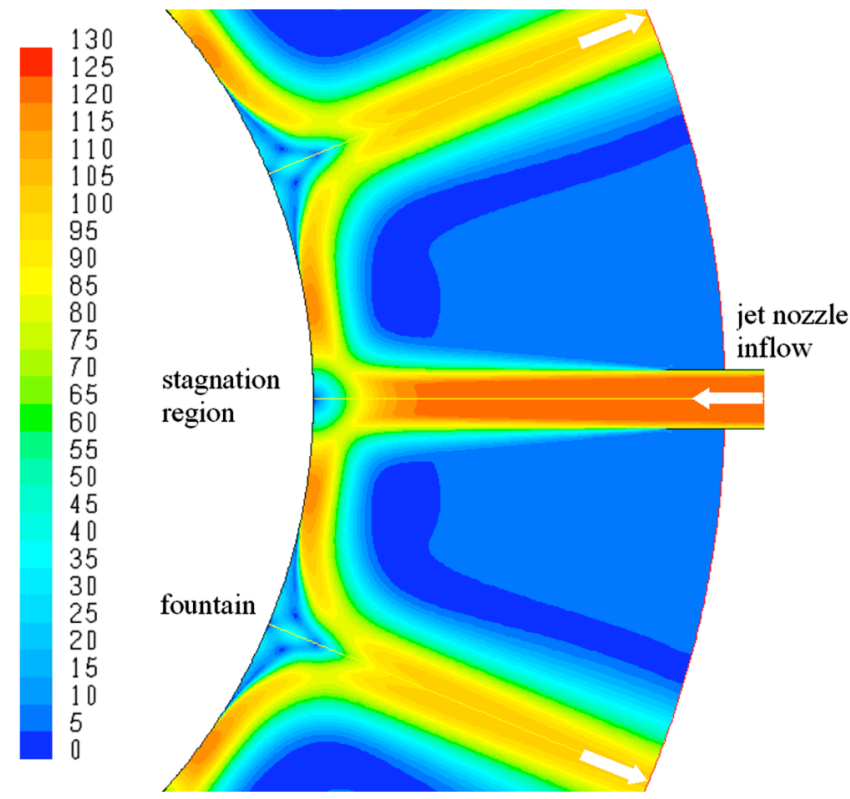

Fig. 20 Velocity magnitude contours, $\mathrm{m} / \mathrm{s}$, for the $R e=80,000$, $d / D=10, H / 2 B=3, n=8$ case.

The interaction of the velocity field and heat transfer profile is visualized by a superimposed plot of the Nusselt number and the velocity field, shown in Fig. 16 for half of the cylindrical target. The secondary peaks in the Nusselt number profiles had different locations in the cylindrical target case than in the flat-plate case. Further investigation showed that in the cylindrical target case, the curvature of the wall caused a thickening of the boundary layer and that the region of high turbulent kinetic energy did not spread laterally rapidly enough to make up for the turning of the wall. Figure 17 shows that although a region of high turbulent kinetic energy occurred, it did not contact the wall in the fashion seen for the flat wall in Fig. 6. The secondary peak seen in the cylindrical target Nusselt number profile was instead the result of flow separation and rotating flows in the fountain region. It was seen that for much lower curvature, such as $20<d / D<40$, a secondary peak could appear near the stagnation region as well as one in the fountain region. In the high-curvature range of $5<d / D<10$ used in this study, the Nusselt number near the stagnation region did not show the secondary peaks seen for targets with flat surfaces.

\section{Recirculation Region}

The recirculation region was characterized by the highest turbulence in the flowfield, seen in Fig. 21 to reach $150 \%$ of that found in the wall jet. The two colliding jets formed a backflow fountain with vortices induced underneath the fountain, shown in Fig. 22. These vortices scrubbed the surface in the region of reversed flow below the fountain, transporting energy away from the wall without the hindrance of a thick developed boundary layer.

It is noteworthy that these results differ somewhat from those expected from the standard $k-\varepsilon$ model, known to improperly predict the separation points and downstream effects in separated flows. Both the $k-\varepsilon$ and $v^{2} f$ models will predict a turbulent recirculation region with heightened heat transfer rates. The $v^{2} f$ model was developed with such flows in mind, and has been shown to yield good predictions of skin friction, $k, \varepsilon$, and velocity profiles in a number of geometries involving separation, recirculation, and boundary layers on curved surfaces $[24,25]$. Even so, the $v^{2} f$ model was similarly limited by employing time-averaged equations, and could not perfectly model the flow in this region. The collision of the two wall jets is a type of flow expected to have large-scale eddies (vortices or vortex tubes along the out-of-plane $z$ axis) with diameters on the order of $D$. This flow was not expected to be completely steady or stable. This fountain region was certainly expected to be a turbulent, disturbed flow, with minimal steady boundary layer 


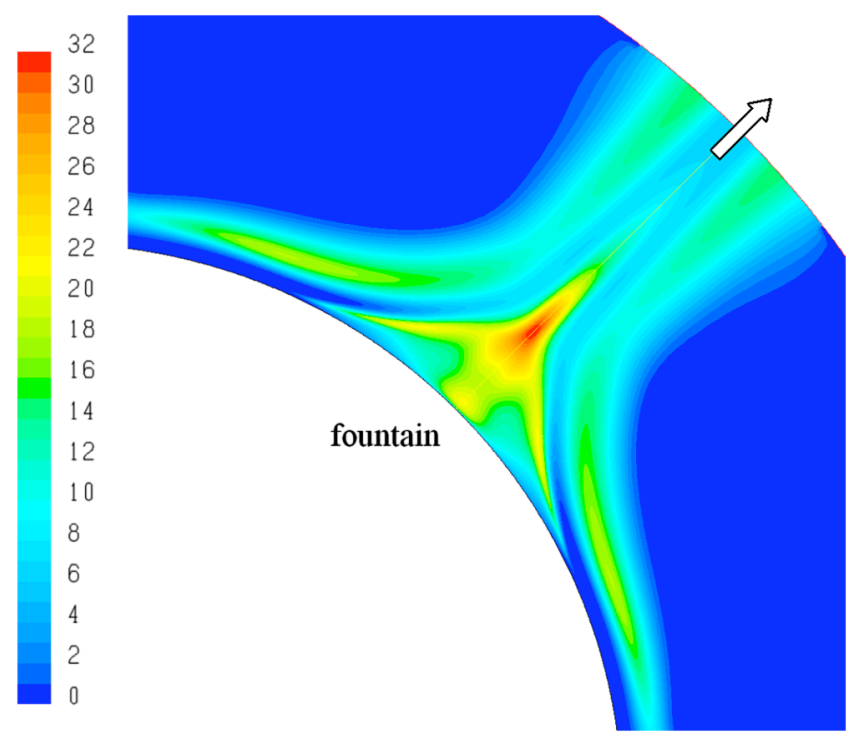

Fig. 21 Turbulent kinetic energy $k\left(\mathrm{in} \mathrm{m}^{2} / \mathrm{s}^{2}\right)$ in the jet fountain, for the $R e=20,000, d / D=10, H / 2 B=3, n=4$ case.

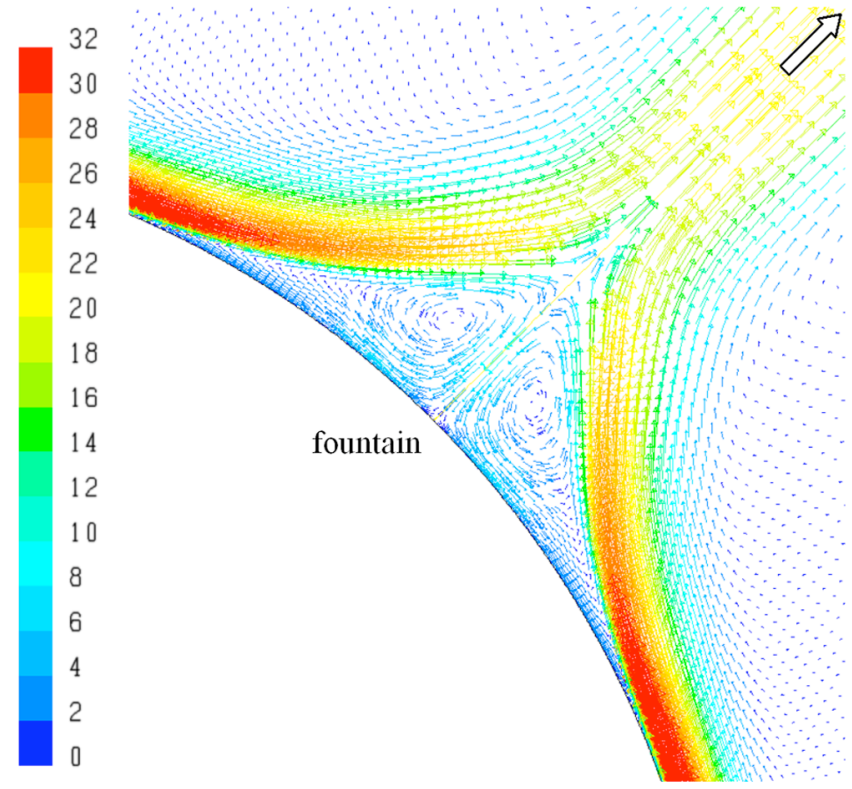

Fig. 22 Velocity vectors in the recirculation region around the impinging jet (fountain region) shown for the $R e=20,000, d / D=10$, $H / 2 B=3, n=4$ case, scale in $\mathrm{m} / \mathrm{s}$ (shown at coarser resolution than mesh spacing).

impeding heat transfer. Based on the aforementioned $v^{2} f$ validation work performed, this case still had an unavoidable modeling error.

This computed pattern of variation in Nusselt number has also been found in experimental measurements: Can et al. [28] showed secondary peaks in the Nusselt number occurring in the region between adjacent slot jets, and similar effects were found in the particle image velocimetry (PIV) measurements by Geers et al. [29] of the flowfield of an array of round impinging jets, in which wall jets collided and established recirculatory fountains. The measurements of $k$ at a position $0.25 D$ above the target surface showed levels of $k$ three times higher in the fountain than in the stagnation region. An impinging jet heat transfer experiment by Slayzak et al. [30] measured the fountain effects of slots jets in water with $R e$ from 24,000 to 51,000 . The experiment used jet guards to limit interaction of the freejet shear layer and the fountain, so that the transfer effects in the fountain resulted from the collision of two wall jets without external influences. The heat transfer profiles on the heated wall surface showed a single peak under each impinging jet and a peak of the same magnitude centered under the fountain. The experimental information confirmed that the fountain is indeed a region of high turbulence and large-scale flow oscillation. Slayzak et al. concluded that there is a local maximum in the heat transfer coefficient $h$ within the stable interaction zone, which is comparable to values associated with $h$ in the impingement zone [30]. In a related experiment by Korger and Krizek [31], the naphthalene sublimation rates under a slot jet array showed the same fountain effect. The sublimation patterns of this turbulent flow ( $R e$ from 6,040 to 37,800) had a peak in the transfer coefficient halfway between each slot jet, with the same height and half-width as was measured for the primary peak immediately under each slot nozzle. The work of both Slayzak et al. and Korger and Krizek showed that for some geometries and flow conditions the local Nusselt number in the stagnation region and fountain regions should be of similar magnitude. As seen in Fig. 19, the calculated Nusselt number values in the fountain were at least as high as those in the stagnation region, and the Nusselt number in the fountain increased with $n$. This resulted from the effects of boundary layer separation. The patterns and relative magnitude of heat transfer coefficients predicted by this CFD model compared well with those found in laboratory research of the same phenomena.

\section{E. Sensitivity Analysis}

The tabulated computed results are shown in the Appendix to this paper, and the trends seen from their examination are discussed in this section. As expected, the average Nusselt number showed a continuous rise with rising Reynolds number, for all cases modeled. An example of the relative influence of $n$ and Reynolds number upon $N u_{\text {avg }}$ is shown in Fig. 23.

As seen in the tabulated results, for cases with small nozzles $(d / D=10)$ with $n=6$ and $n=8$, the increase of Reynolds number increased $N u_{\max } / N u_{\min }$ for $R e$ up to 40,000. This ratio decreased for higher $\operatorname{Re}(80,000)$. This was not the case for the $n=4$ and $n=2$ cases, which had different resulting physics. In the $n=2$ cases the flow remained attached along the surface of the target in a wall jet for over $60 \%$ of the surface area, with the maximum-velocity region of the wall jet within one nozzle height of the wall over $80 \%$ of the target surface; in the $n=8$ case the wall jet covered only $30 \%$ of the wall; the impinging jet and fountain flow covered $70 \%$ of the circumferential span of the wall surface, each filling $35 \%$ of this space.

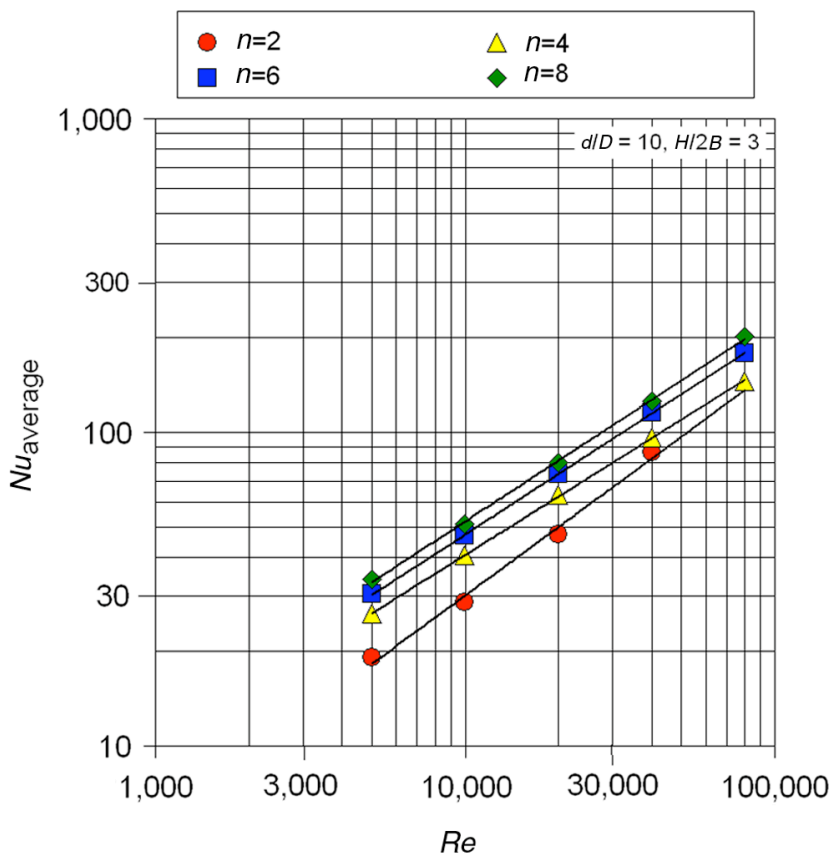

Fig. 23 Variation of $N u_{\text {avg }}$ vs $R e$ and $n$ for sample case with $d / D=10$, $H / 2 B=3$. 
The different nozzle configurations produced different spatial extents of each portion of the flow field. In the $n=2$ case the increase in Reynolds number created a larger increase in the turbulence levels above the wall and raised the minimum Nusselt number, more rapidly than it raised the stagnation region Nusselt number. In the cases with more nozzles, the wall jet was smaller and less circumferential distance was available for development of a turbulent layer. Instead the higher Reynolds number mainly increased the stagnation region Nusselt number and increased turbulence within the fountain. In the cases with $d / D=5$, the wider nozzle, stagnation region, wall jet, and fountain created a flow where the wall-jet thickness was greater relative to its length and there was less streamwise length for development of turbulence above the wall.

As the Reynolds number was increased, a trend of decreasing $N u_{\max } / N u_{\min }$ for many $n=2$ cases resulted from the influence on Nusselt number of the turbulent shear layer in the wall jet. Because of the geometry, $N u_{\text {avg }}$ in this flow was not as highly influenced by the jet fountain because it covered a smaller portion of the target surface. It was more influenced by the wall jet, which at higher Reynolds number and higher streamwise (azimuthal) coordinates developed sufficient turbulence to improve local heat transfer. This effect diminished with decreasing $d / D$.

The inclusion of additional jets, raising the number of jets to $n=6$ or $n=8$, produced moderate improvement in the overall heat transfer rate. For example, at $n=8$ and $R e=20,000$, the mass flow impinging on the target cylinder increased by a factor of 2 , and $h$ increased by a factor of only 1.27. At the same nozzle size, this meant that doubling of the blower power increased $h$ by only $27 \%$. From a design perspective in which the goal is to produce a value of $h$, increasing the number of jets is likely to increase power demand. For example, changing the value of $n$ from 4 to 6 while adjusting the Reynolds number to meet the same $N u_{\text {avg }}$ required $40-50 \%$ more power.

The increase in $n$ caused higher jet interference effects and earlier separation. The static pressure accumulation under the fountain influenced the flowfield over half the wall. The net effect of changing $n$ at a constant fluid flow or constant power was to increase the uniformity of $h$ while decreasing $h_{\text {avg }}$. As discussed in the following paragraphs, $h_{\text {avg }}$ was found to be more sensitive to the Reynolds number than to $n$, whereas power requirements are extremely sensitive to Reynolds number. At a given choice of $n$ and $B$, the value of the Nusselt number or $h$ may grow in proportion to $R e^{0.66}$, whereas the necessary power grows in proportion to $R e^{3}$. This effect is illustrated by Figs. 24 and 25, in which the curved lines represent curve fits through the data points, illustrating the trend of the data.

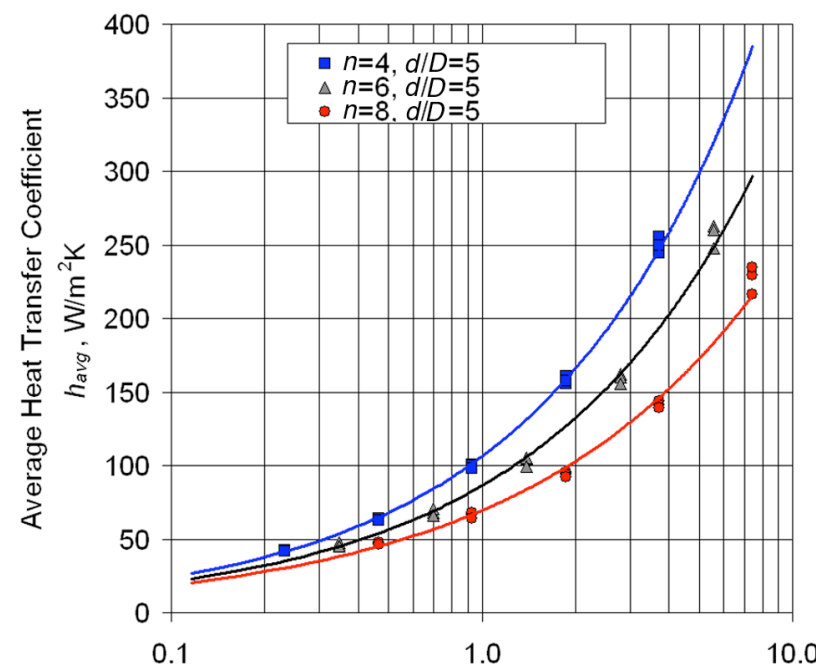

Volumetric Flow per Unit of Target Surface Area $(Q / A), \mathrm{m} / \mathrm{s}$

Fig. 24 Area-averaged heat transfer coefficient $h_{\text {avg }}$ vs volumetric flow per unit surface area $Q / A$, provided for the cylindrical target under radial slot jets, $1 \leq H / 2 B \leq 5,5,000 \leq R e \leq 80,000$, air jets.

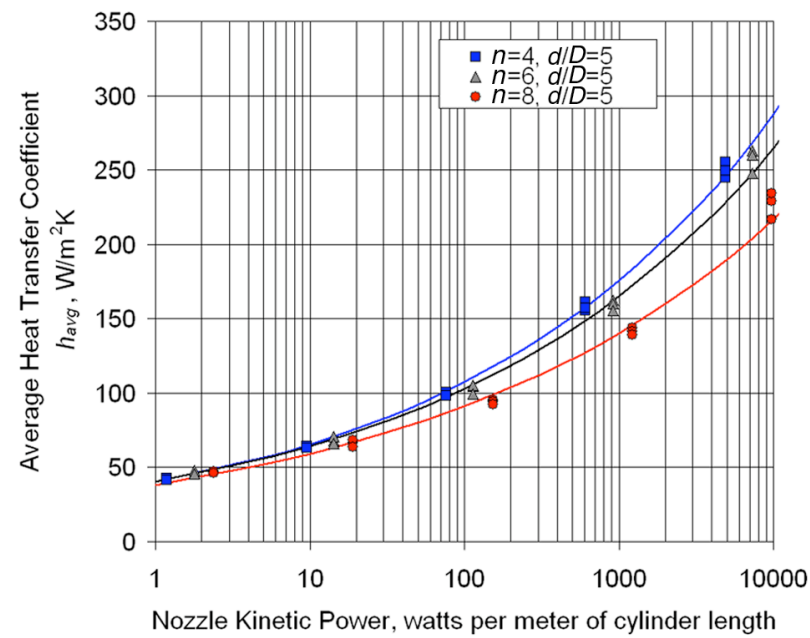

Fig. 25 Area-averaged heat transfer coefficient $h_{\text {avg }}$ vs power invested per meter of cylinder length for the cylindrical target under radial slot jets, $1 \leq H / 2 B \leq 5,5,000 \leq R e \leq 80,000$, air jets.

Figure 24 presents the trend of heat transfer rate (coefficient) vs volumetric flow (per unit of target area) for the various configurations modeled. The curves show that a twofold increase in average heat transfer rate required three-four times the volumetric flow. It is also clear that increasing the number of jets at a constant fluid volumetric flow resulted in an overall reduction of $h$, as decreases in Reynolds number outpaced the benefits of reducing the wall-jet circumferential span. However, the increase in the number of jets will produce a pattern with more closely spaced peaks and valleys in the Nusselt number profile, which will directly influence the temperature distribution within the target.

A similar trend of diminishing returns is visible in the curves of heat transfer coefficient $h$ vs nozzle power per meter of cylindrical section length, shown in Fig. 25. Once again it is seen that increasing $n$ increased the jet interference and diminished the overall averaged transfer rate $h_{\text {avg }}$ when limiting the total nozzle flow to a set kinetic power. Despite this trend, the ultimate application must be considered, because there may be cases where the investment of additional power yields minimal increase in Nusselt number but more uniform values of $T$ within the target. One should note that similar trends exist for other cooling configurations.

In a case where the jet number decreases to the minimum of $n=1$, the target would have a large separated flow region on the side opposite the jet. This would result in nonuniform heat transfer with none of the benefits that occur with a wall-jet fountain. For this reason it is of practical interest to use at least two jet nozzles. Based on Fig. 24, for applications with a set mass flow, the $n=2$ configuration offered the highest heat transfer rates. For applications with a set nozzle power, the $n=4$ configuration offered better transfer rates.

\section{F. Error Associated with Variation in Fluid Properties}

The models used constant fluid properties throughout the entire flow domain and had a small temperature difference between the wall and fluid. Inlet fluid temperature was $300 \mathrm{~K}$ and wall temperature was typically set at $310 \mathrm{~K}$. To investigate the error associated with the variation of fluid properties, the model was run with constant fluid properties at an incoming jet temperature maintained at $300 \mathrm{~K}$ but with the cylinder wall temperature elevated to different levels, for the $n=4, d / D=10, H / 2 B=3$ case at a fixed $R e$ of 20,000 . For each case the fluid properties were set to those of air at the average between the wall and the inflow jet temperatures. The dependent variables $N u_{\text {avg }}, N u_{\text {max }} / N u_{\min }$, and $\left(N u_{\max }-N u_{\min }\right) / N u_{\text {avg }}$ were tracked vs the temperature ratio $\mathrm{TR}=\left(T_{\text {wall }} / T_{\text {jet }}\right)$. The area-weighted normalized standard deviation of the Nusselt number was computed using the formula 


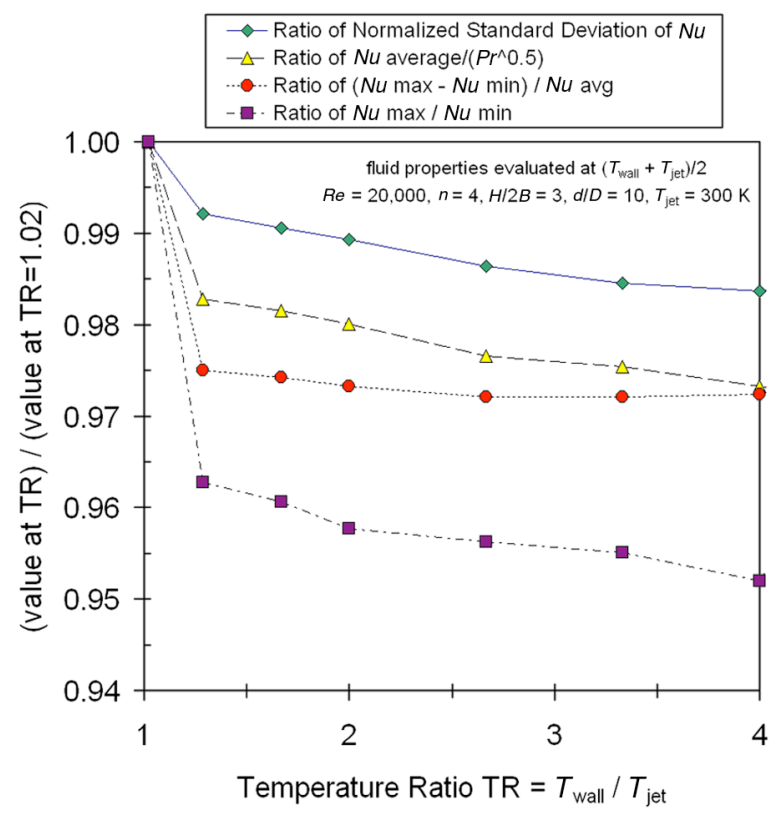

Fig. 26 Variation in magnitude and nonuniformity of Nusselt number vs fluid temperature ratio.

$$
\sigma=\frac{\sqrt{\left[\sum_{i}\left(N u_{i}-N u_{\mathrm{avg}}\right)^{2} \Delta A_{i}\right] /\left(\sum_{i} \Delta A_{i}\right)}}{N u_{\mathrm{avg}}}
$$

where $\Delta A_{i}$ represented the surface area of one cell on the target (with unit depth) and $i$ was the cell index. Each of these dependent variables was compared to the value of the variable at $\mathrm{TR}=1.02$. This reference TR value was selected to be small, but greater than 1 , as $N u$ would be 0 at TR $=1$. Figure 26 shows the trends in the results for each of the four dependent parameters. The errors in each of the parameters tended to increase with TR. The change in $N u_{\text {avg }}$ reached $3 \%$ at $\mathrm{TR}=4$. From this we can conclude that there is some expected error when using the results shown herein at large temperature ratios. For $1<\mathrm{TR} \leq 4$, this error is expected to be up to $3 \%$ for $N u_{\text {avg }}, 5 \%$ for $N u_{\max } / N u_{\min }, 2.5 \%$ for $\left(N u_{\max }-N u_{\min }\right) / N u_{\mathrm{avg}}$, and $1.4 \%$ for $\sigma$. In all cases the variation of fluid properties with temperature was seen to be a second-order effect. This potential error was thus an order of magnitude below the modeling error.

\section{G. Summary of Effects of Parametric Variation}

Table 2 summarizes the effects of changing each of the parametric variables for the configuration studied.

\section{Combined Correlation}

The results of the data were compiled into a combined correlation equation of the general form

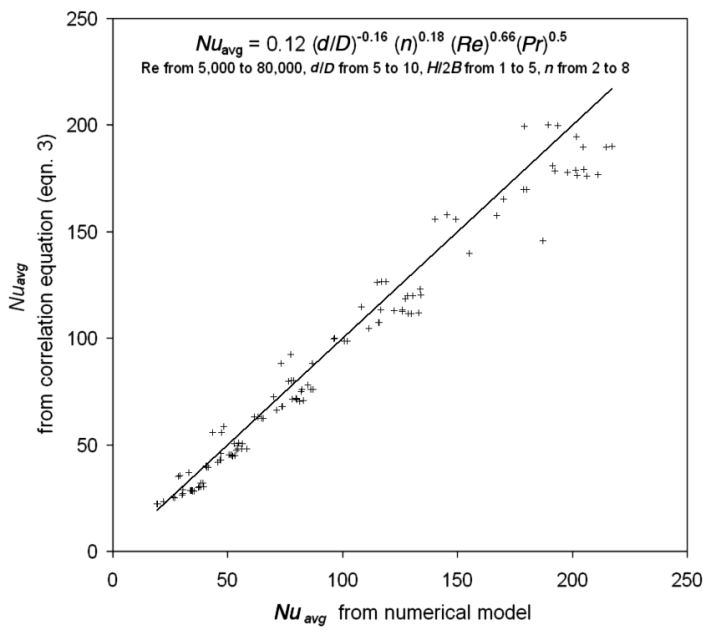

Fig. 27 Comparison of the correlation equation [Eq. (3)] with the computed results.

$$
N u_{\mathrm{avg}}=a_{1}\left(\frac{d}{D}\right)^{a_{2}}\left(\frac{H}{2 B}\right)^{a_{3}}(n)^{a_{4}}(\operatorname{Re})^{a_{5}}(\operatorname{Pr})^{a_{6}}
$$

where the various $a$ were constants to be determined.

The value of the exponent $a_{6}$ was set by an independent parametric study. The model was first run using different fluids, while holding $d / D, H / 2 B, n$, and $R e$ constant. In addition to air at $1 \mathrm{~atm}, 300 \mathrm{~K}$, the other fluids selected were pure steam at $1 \mathrm{~atm}, 393.15 \mathrm{~K}$ $(P r=0.994)$, and liquid water at 1 atm, $300 \mathrm{~K}(P r=5.85)$. Following this, additional runs were made while holding $\mu, \rho$, and $c_{p}$ constant and varying $k_{c}$. This procedure was repeated for different values of $d / D, H /(2 B), R e$, and $n$, over a range of $\operatorname{Pr}$ from $P r=0.5$ to $\operatorname{Pr}=1$. The resulting values of the Nusselt number gave values of $a_{6}$ in the range of 0.46 to 0.52 . From these results the value of $a_{6}$ was selected as 0.5 . This may be compared with the results of $\mathrm{Li}$ and Garimella [32], whose experimental work found that for a confined slot jet on a flat surface, $N u \propto P r^{0.452}$. Numerous studies of this relationship have found the exponent to vary a small amount with both Prandtl number and Reynolds number, much as the exponent $b$ in the relation $N u \propto R e^{b}$ is not truly constant, but varies with the Reynolds number.

The complete data set was used to generate a least-squares curve fit to determine the exponents in Eq. (3). It was found that for the geometry selected, with a flat initial velocity profile and a supply nozzle of length $10 D$, the solutions were insensitive to nozzle height for values of $H /(2 B)$ from 1 to 5 , and $a_{3}=1$ was therefore assumed. This produced the correlation equation

$$
N u_{\text {avg }}=0.12\left(\frac{d}{D}\right)^{-0.16}(n)^{0.18}(\operatorname{Re})^{0.66}(\operatorname{Pr})^{0.5}
$$

This equation is a tool for use in initial predictions, and it should be

\begin{tabular}{|c|c|}
\hline Variable & Effects \\
\hline$R e$ & $R e$ was the dominant variable for influencing heat transfer and power required. $N u \propto R e^{0.66}$ \\
\hline$d / D$ & $\begin{array}{l}\text { Of secondary importance. Increasing target diameter or decreasing nozzle size } \\
\text { at a constant } R e \text { lowered } N u .\end{array}$ \\
\hline$n$ & Increased uniformity of $N u$ profile giving closer peaks and valleys with smaller circumferential spans. \\
\hline & $\begin{array}{l}\text { Increasing } n \text { at a set } R e \text { increased power and flow required while reducing the portion of the } \\
\text { target covered by wall-jet boundary layer. This caused an increase in } N u \text {, found to } \\
\text { follow the relation } N u \propto n^{0.18}\end{array}$ \\
\hline & Selection of $n$ should be based on both uniformity of $N u$ and efficiency $\left(N u_{\text {avg }} /\right.$ power). \\
\hline$P r$ & $\begin{array}{c}\text { Increasing diffusivity }\left(k_{c}\right) \text { or decreasing viscosity improved transport of heat } \\
\text { through the flow field. } N u \propto P r^{0.5}\end{array}$ \\
\hline$H / 2 B$ & $\begin{array}{l}\text { Of minimal importance for this geometric configuration. Development of turbulence in the freejet } \\
\text { shear layer was less important than in the wall-jet shear layer. }\end{array}$ \\
\hline
\end{tabular}
acknowledged that based on results from prior research, the results

Table 2 Effects of changing parametric variables 
are not expected to collapse well as a function of Reynolds number. Typical experimental data and experimentally derived correlations such as those by Martin [1] and Goldstein et al. [33-35] show the exponent on the Reynolds number ranging from 0.5 to 0.85 . The exponent of 0.66 found here compares with these values well. By the magnitude of its exponent, Eq. (3) reveals the Reynolds number to have the greatest influence on the heat transfer rate among the nondimensional parameters selected. A comparison between the correlation equation and computed results is shown in Fig. 27, in which the diagonal line represents a perfect fit between the data points and the correlation equation.

Based on the range of parameters selected, this expression is valid over the range $2 \leq n \leq 8,5 \leq d / D \leq 10,5,000 \leq R e \leq 80,000$, $0.7 \leq \operatorname{Pr} \leq 5.85$, and $1 \leq H / 2 B \leq 5$. Based on the results of varying fluid properties, the difference in computed $N u_{\text {avg }}$ using variable fluid properties vs using constant fluid properties is expected to be up to $3 \%$ for $1<\mathrm{TR} \leq 4$, as shown in Fig. 26 .

\section{Conclusions}

Numerical models were used to simulate the heat transfer on a cylindrical target under an array of radial impinging slot jets. For modeling selection and validation, results from various models were compared against test data for flat-plate jet impingement heat transfer, and the $v^{2} f$ RANS model was selected based on accuracy and computation speed. An improved understanding of the flowfields and their effects on heat transfer was obtained. Modeling of the cylindrical target yielded a correlation capable of predicting heat transfer on a cylindrical target over a range of parametric variables.

From the parametric modeling it was found that fountain effects played a major role in the heat transfer on the target, influencing as much as one-third of the target surface. Reynolds number effects dominated over the effect of the number of jets when attempting to increase $N u_{\text {avg }}$. It was concluded that the highest $N u_{\text {avg }}$ per unit of power or flow invested would occur when having a lower number of jets ( $n=2$ or 4$)$. Cooling arrangements with six and eight nozzles had similar levels of nonuniformity of the Nusselt number. Increasing $n$ at a given Reynolds number tended to increase $N u_{\text {avg }}$. The area-averaged Nusselt number data were combined into a single correlation between Nusselt number, jet-to-cylinder diameter ratio, Reynolds number, number of jets, and the Prandtl number.

\section{Appendix: Computational Results}

Tables A1-A7 list details of the computational results.
Table A2 Computational results for $d / D=5, H / 2 B=3$

\begin{tabular}{lrrc}
\hline \hline$n$ & \multicolumn{1}{c}{$R e$} & $N u_{\text {avg }}$ & $N u_{\text {max }} / N u_{\text {min }}$ \\
\hline 2 & 5,000 & 27 & 11.6 \\
2 & 10,000 & 42 & 10.7 \\
2 & 20,000 & 65 & 12.5 \\
2 & 80,000 & 140 & 5.7 \\
4 & 5,000 & 35 & 6.7 \\
4 & 20,000 & 83 & 7.8 \\
4 & 40,000 & 128 & 8.9 \\
4 & 80,000 & 202 & 9.6 \\
6 & 5,000 & 40 & 7.0 \\
6 & 10,000 & 58 & 6.5 \\
6 & 20,000 & 87 & 7.3 \\
6 & 40,000 & 131 & 8.8 \\
6 & 80,000 & 215 & 9.7 \\
8 & 5,000 & 39 & 6.4 \\
8 & 10,000 & 56 & 7.2 \\
8 & 20,000 & 78 & 6.5 \\
8 & 40,000 & 117 & 8.3 \\
8 & 80,000 & 194 & 9.1 \\
\hline \hline
\end{tabular}

Table A3 Computational results for $d / D=5, H / 2 B=5$

\begin{tabular}{lrrr}
\hline \hline$n$ & \multicolumn{1}{c}{$R e$} & $N u_{\text {avg }}$ & $N u_{\max } / N u_{\min }$ \\
\hline 4 & 5,000 & 35 & 8.2 \\
4 & 10,000 & 52 & 7.5 \\
4 & 20,000 & 81 & 8.9 \\
4 & 40,000 & 130 & 9.9 \\
4 & 80,000 & 206 & 12.1 \\
6 & 5,000 & 38 & 7.4 \\
6 & 10,000 & 54 & 7.1 \\
6 & 20,000 & 82 & 8.0 \\
6 & 40,000 & 128 & 9.6 \\
6 & 80,000 & 205 & 10.7 \\
8 & 5,000 & 38 & 7.5 \\
8 & 10,000 & 53 & 8.1 \\
8 & 20,000 & 76 & 7.8 \\
8 & 40,000 & 115 & 8.9 \\
8 & 80,000 & 179 & 10.2 \\
\hline \hline
\end{tabular}

Table A1 Computational results for $d / D=5, H / 2 B=1$

\begin{tabular}{lrrr}
\hline \hline$n$ & \multicolumn{1}{c}{$R e$} & $N u_{\text {avg }}$ & $N u_{\max } / N u_{\min }$ \\
\hline 2 & 5,000 & 27 & 10.3 \\
2 & 10,000 & 41 & 9.7 \\
2 & 20,000 & 65 & 11.5 \\
2 & 80,000 & 149 & 5.6 \\
4 & 5,000 & 35 & 6.4 \\
4 & 10,000 & 53 & 6.8 \\
4 & 20,000 & 83 & 8.1 \\
4 & 40,000 & 133 & 8.8 \\
4 & 80,000 & 211 & 10.4 \\
6 & 5,000 & 38 & 5.5 \\
6 & 10,000 & 56 & 5.9 \\
6 & 20,000 & 86 & 6.7 \\
6 & 40,000 & 134 & 7.9 \\
6 & 80,000 & 217 & 9.3 \\
8 & 5,000 & 38 & 6.0 \\
8 & 10,000 & 55 & 6.2 \\
8 & 20,000 & 79 & 6.3 \\
8 & 40,000 & 119 & 7.8 \\
8 & 80,000 & 189 & 9.4 \\
\hline \hline
\end{tabular}

Table A4 Computational results for $d / D=7.5, H / 2 B=3$

\begin{tabular}{lrrr}
\hline \hline$n$ & $R e$ & $N u_{\text {avg }}$ & $N u_{\max } / N u_{\text {min }}$ \\
\hline 2 & 5,000 & 22 & 16.2 \\
2 & 10,000 & 33 & 11.1 \\
2 & 20,000 & 48 & 5.3 \\
2 & 40,000 & 77 & 4.4 \\
2 & 80,000 & 187 & 4.3 \\
4 & 5,000 & 29 & 11.5 \\
4 & 10,000 & 46 & 8.3 \\
4 & 20,000 & 71 & 9.3 \\
4 & 40,000 & 111 & 11.8 \\
4 & 80,000 & 170 & 11.2 \\
6 & 5,000 & 34 & 9.3 \\
6 & 10,000 & 52 & 6.7 \\
6 & 20,000 & 80 & 7.8 \\
6 & 40,000 & 126 & 8.4 \\
6 & 80,000 & 198 & 9.2 \\
8 & 5,000 & 36 & 8.3 \\
8 & 10,000 & 54 & 5.7 \\
8 & 20,000 & 82 & 6.7 \\
8 & 40,000 & 127 & 7.8 \\
\hline \hline
\end{tabular}


Table A5 Computational results for $d / D=10, H / 2 B=1$

\begin{tabular}{lrrr}
\hline \hline$n$ & \multicolumn{1}{c}{$R e$} & $N u_{\text {avg }}$ & $N u_{\text {max }} / N u_{\text {min }}$ \\
\hline 2 & 5,000 & 19 & 13.1 \\
2 & 10,000 & 29 & 11.7 \\
2 & 20,000 & 43 & 9.4 \\
2 & 40,000 & 73 & 4.3 \\
2 & 80,000 & 155 & 3.4 \\
4 & 5,000 & 26 & 9.8 \\
4 & 6,125 & 30 & 8.4 \\
4 & 12,250 & 47 & 9.3 \\
4 & 24,500 & 70 & 11.0 \\
4 & 49,000 & 108 & 9.5 \\
4 & 98,000 & 191 & 5.7 \\
6 & 5,000 & 31 & 8.0 \\
6 & 12,250 & 54 & 8.2 \\
6 & 24,500 & 85 & 9.1 \\
6 & 49,000 & 134 & 11.6 \\
6 & 98,000 & 202 & 9.8 \\
8 & 5,000 & 34 & 6.4 \\
8 & 10,000 & 52 & 7.2 \\
8 & 20,000 & 80 & 8.9 \\
8 & 40,000 & 117 & 18.2 \\
8 & 80,000 & 205 & 11.2 \\
\hline \hline
\end{tabular}

Table A6 Computational results for $d / D=10, H / 2 B=3$

\begin{tabular}{lrrr}
\hline \hline$n$ & \multicolumn{1}{c}{$R e$} & $N u_{\text {avg }}$ & $N u_{\max } / N u_{\min }$ \\
\hline 2 & 5,000 & 19 & 14.0 \\
2 & 10,000 & 29 & 6.0 \\
2 & 20,000 & 47 & 5.1 \\
2 & 40,000 & 87 & 3.9 \\
4 & 5,000 & 26 & 9.5 \\
4 & 10,000 & 40 & 8.5 \\
4 & 20,000 & 63 & 10.4 \\
4 & 40,000 & 96 & 13.6 \\
4 & 80,000 & 145 & 11.2 \\
6 & 5,000 & 30 & 8.0 \\
6 & 10,000 & 47 & 8.4 \\
6 & 20,000 & 73 & 9.6 \\
6 & 40,000 & 115 & 11.9 \\
6 & 80,000 & 179 & 13.7 \\
8 & 5,000 & 34 & 7.0 \\
8 & 10,000 & 51 & 7.6 \\
8 & 20,000 & 80 & 8.6 \\
8 & 40,000 & 126 & 9.7 \\
8 & 80,000 & 202 & 10.3 \\
\hline \hline
\end{tabular}

Table A7 Computational results for $d / D=10, H / 2 B=5$

\begin{tabular}{lrrc}
\hline \hline$n$ & \multicolumn{1}{c}{$R e$} & $N u_{\text {avg }}$ & $N u_{\max } / N u_{\text {min }}$ \\
\hline 4 & 5,000 & 26 & 9.9 \\
4 & 10,000 & 41 & 8.4 \\
4 & 20,000 & 62 & 7.8 \\
4 & 40,000 & 96 & 3.6 \\
4 & 80,000 & 167 & 4.2 \\
4 & 5,000 & 30 & 8.9 \\
6 & 10,000 & 47 & 8.2 \\
6 & 20,000 & 74 & 9.3 \\
6 & 40,000 & 116 & 10.4 \\
6 & 80,000 & 180 & 12.1 \\
8 & 5,000 & 34 & 7.3 \\
8 & 10,000 & 51 & 7.5 \\
8 & 20,000 & 78 & 8.3 \\
8 & 40,000 & 122 & 9.3 \\
8 & 80,000 & 192 & 10.1 \\
\hline \hline
\end{tabular}

\section{Acknowledgment}

Technical support related to software setup and modeling was provided by Fluent, Inc.

\section{References}

[1] Martin, H., "Heat and Mass Transfer Between Impinging Gas Jets and Solid Surfaces," Advances in Heat Transfer, Vol. 13, 1977, pp. 160.

[2] Viskanta, R., "Heat Transfer to Impinging Isothermal Gas and Flame Jets," Experimental Thermal and Fluid Science, Vol. 6, No. 2, 1993, pp. 111-134.

[3] Jambunathan, K., Lai, E., Moss, M. A., and Button, B. L., "A Review of Heat Transfer Data for Single Circular Jet Impingement," International Journal of Heat and Fluid Flow, Vol. 13, No. 2, 1992, pp. 106115 .

[4] Zuckerman, N., and Lior, N., "Jet Impingement Heat Transfer: Physics, Correlations, and Numerical Modeling," Advances in Heat Transfer (submitted for publication).

[5] Olsson, E. E. M., Ahrné, L. M., and Trägårdh, A. C., "Flow and Heat Transfer from Multiple Slot Air Jets Impinging on Circular Cylinders," Journal of Food Engineering, Vol. 67, No. 3, 2005, pp. 273280.

[6] Zuckerman, N., and Lior, N., "Impingement Heat Transfer: Correlations and Numerical Modeling," Journal of Heat Transfer, Vol. 127, No. 5, 2005, pp. 544-552.

[7] Fluent 6.1 User's Guide, Fluent, Inc., Lebanon, NH, Jan. 2003.

[8] Baughn, J. W., and Shimizu, S., "Heat Transfer Measurements from a Surface with Uniform Heat Flux and an Impinging Jet," Journal of Heat Transfer, Vol. 111, No. 4, 1989, pp. 1096-1098.

[9] Baughn, J. W., Hechanova, A., and Yan, X., "An Experimental Study of Entrainment Effects on the Heat Transfer from a Flat Surface to a Heated Circular Impinging Jet," Journal of Heat Transfer, Vol. 113, No. 44, 1991, pp. 1023-1025.

[10] Esch, T., Menter, F., and Vieser, W., "Heat Transfer Predictions Based on Two-Equation Turbulence Models," TED Paper AJ03-542, March 2003.

[11] Shih, T.-H., Liou, W. W., Shabbir, A., Yang, Z., and Zhu, J., "A New k- $\varepsilon$ Eddy-Viscosity Model for High Reynolds Number Turbulent Flows -Model Development and Validation," Computers and Fluids, Vol. 24, No. 3, 1995, pp. 227-238.

[12] Launder, B. E., and Spalding, D. B., "The Numerical Computation of Turbulent Flows," Computer Methods in Applied Mechanics and Engineering, Vol. 3, No. 2, 1974, pp. 269-289.

[13] Jayatilleke, C., "The Influence of Prandtl Number and Surface Roughness on the Resistance of the Laminar Sublayer to Momentum and Heat Transfer," Progress in Heat and Mass Transfer, Vol. 1, 1969, pp. 193-321.

[14] Kim, S.-E., and Choudhury, D., "A Near-Wall Treatment Using Wall Functions Sensitized to Pressure Gradient," ASME FED Vol. 217, Separated and Complex Flows, American Society of Mechanical Engineers, New York, 1995, pp. 273-280.

[15] White, F., and Christoph, G., "A Simple New Analysis of Compressible Turbulent Skin Friction Under Arbitrary Conditions," U.S. Air Force Flight Dynamics Laboratory, Tech. Rept. AFFDL-TR-70-133, WrightPatterson AFB, OH, Feb. 1971.

[16] Huang, P., Bradshaw, P., and Coakley, T., "Skin Friction and Velocity Profile Family for Compressible Turbulent Boundary Layers," AIAA Journal, Vol. 31, No. 9, 1993, pp. 1600-1604.

[17] Launder, B. E., Reece, G. J., and Rodi, W., "Progress in the Development of a Reynolds-Stress Turbulence Closure," Journal of Fluid Mechanics, Vol. 68, No. 3, 1975, pp. 537-566.

[18] Gibson, M. M., and Launder, B. E., "Ground Effects on Pressure Fluctuations in the Atmospheric Boundary Layer," Journal of Fluid Mechanics, Vol. 86, No. 3, 1978, pp. 491-511.

[19] Fu, S., Launder, B. E., and Leschziner, M. A., "Modeling Strongly Swirling Recirculating Jet Flow with Reynolds-Stress Transport Closures," Sixth Symposium on Turbulent Shear Flows, Pennsylvania State Univ., University Park, PA, 1987, pp. 17.6.1-17.6.6.

[20] Launder, B. E., "Second-Moment Closure and Its Use in Modeling Turbulent Industrial Flows," International Journal for Numerical Methods in Fluids, Vol. 9, No. 8, 1989, pp. 963-985.

[21] Launder, B. E., "Second-Moment Closure: Present... and Future?," International Journal of Heat and Fluid Flow, Vol. 10, No. 4, 1989, pp. 282-300.

[22] Wilcox, D. C., Turbulence Modeling for CFD, 1st ed., DCW Industries, La Canada, CA, 1998.

[23] Launder, B. E., and Spalding, D. B., Lectures in Mathematical Models of Turbulence, Academic Press, London, 1972.

[24] Durbin, P., "Separated Flow Computations with the k- $-\varepsilon-v^{2}$ Model," AIAA Journal, Vol. 33, No. 4, 1995, pp. 659-664.

[25] Durbin, P. A., "A Reynolds Stress Model for Near-Wall Turbulence," Journal of Fluid Mechanics, Vol. 249, April 1993, pp. 465-498. 
[26] Behnia, M., Parneix, S., Shabany, Y., and Durbin, P. A., "Numerical Study of Turbulent Heat Transfer in Confined and Unconfined Impinging Jets," International Journal of Heat and Fluid Flow, Vol. 20, No. 1, 1999, pp. 1-9.

[27] Zuckerman, N., and Lior, N., "Jet Impingement Heat Transfer on a Circular Cylinder by Radial Slot Jets," ASME Paper IMECE200579565, Nov. 2005.

[28] Can, M., Etemoĝlu, A. B., and Avci, A., "Experimental Study of Convective Heat Transfer Under Arrays of Impinging Air Jets from Slots and Circular Holes," International Journal of Heat and Mass Transfer, Vol. 38, No. 2, 2002, pp. 251-259.

[29] Geers, L. F. G., Tummers, M. J., and Hanjalić, K., "Experimental Investigation of Impinging Jet Arrays," Experiments in Fluids, Vol. 36, No. 6, 2004, pp. 946-958.

[30] Slayzak, S. J., Viskanta, R., and Incropera, F. P., "Effects of Interaction Between Adjacent Free Surface Planar Jets on Local Heat Transfer from the Impingement Surface," International Journal of Heat and Mass Transfer, Vol. 37, No. 2, 1994, pp. 269-282.
[31] Korger, M., and Krizek, F., "Mass-Transfer Coefficient in Impingement Flow from Slotted Nozzles," International Journal of Heat and Mass Transfer, Vol. 9, No. 4, 1966, pp. 337-344.

[32] Li, C.-Y., and Garimella, S. V., "Prandtl-Number Effects and Generalized Correlations for Confined and Submerged Jet Impingement," International Journal of Heat and Mass Transfer, Vol. 43, No. 18, 2001, pp. 3471-3480.

[33] Goldstein, R. J., and Behbahani, A. I., "Impingement of a Circular Jet with and Without Crossflow," International Journal of Heat and Mass Transfer, Vol. 25, No. 9, 1982, pp. 1377-1382.

[34] Goldstein, R. J., Behbahani, A. I., and Heppelmann, K. K., "Streamwise Distribution of the Recovery Factor and the Local Heat Transfer Coefficient to an Impinging Circular Air Jet," International Journal of Heat and Mass Transfer, Vol. 29, No. 8, 1986, pp. 1227-1235.

[35] Goldstein, R., and Seol, W. S., "Heat Transfer to a Row of Impinging Circular Air Jets Including the Effect of Entrainment," International Journal of Heat and Mass Transfer, Vol. 34, No. 8, 1991, pp. 2133 2147. 